\title{
BLV-CoCoMo-qPCR: Quantitation of bovine leukemia virus proviral load using the CoCoMo algorithm
}

Mayuko Jimba ${ }^{1,2}$, Shin-nosuke Takeshima ${ }^{1}$, Kazuhiro Matoba ${ }^{3}$, Daiji Endoh ${ }^{4}$, Yoko Aida ${ }^{1,2^{*}}$

\begin{abstract}
Background: Bovine leukemia virus (BLV) is closely related to human T-cell leukemia virus (HTLV) and is the etiological agent of enzootic bovine leukosis, a disease characterized by a highly extended course that often involves persistent lymphocytosis and culminates in B-cell lymphomas. BLV provirus remains integrated in cellular genomes, even in the absence of detectable BLV antibodies. Therefore, to understand the mechanism of BLVinduced leukemogenesis and carry out the selection of BLV-infected animals, a detailed evaluation of changes in proviral load throughout the course of disease in BLV-infected cattle is required. The aim of this study was to develop a new quantitative real-time polymerase chain reaction (PCR) method using Coordination of Common Motifs (CoCoMo) primers to measure the proviral load of known and novel BLV variants in clinical animals.
\end{abstract}

Results: Degenerate primers were designed from 52 individual BLV long terminal repeat (LTR) sequences identified from 356 BLV sequences in GenBank using the CoCoMo algorithm, which has been developed specifically for the detection of multiple virus species. Among 72 primer sets from 49 candidate primers, the most specific primer set was selected for detection of BLV LTR by melting curve analysis after real-time PCR amplification. An internal BLV TaqMan probe was used to enhance the specificity and sensitivity of the assay, and a parallel amplification of a single-copy host gene (the bovine leukocyte antigen DRA gene) was used to normalize genomic DNA. The assay is highly specific, sensitive, quantitative and reproducible, and was able to detect BLV in a number of samples that were negative using the previously developed nested PCR assay. The assay was also highly effective in detecting BLV in cattle from a range of international locations. Finally, this assay enabled us to demonstrate that proviral load correlates not only with BLV infection capacity as assessed by syncytium formation, but also with BLV disease progression.

Conclusions: Using our newly developed BLV-CoCoMo-qPCR assay, we were able to detect a wide range of mutated BLV viruses. CoCoMo algorithm may be a useful tool to design degenerate primers for quantification of proviral load for other retroviruses including HTLV and human immunodeficiency virus type 1.

\section{Background}

Many viruses mutate during evolution, which can lead to alterations in pathogenicity and epidemic outbreaks $[1,2]$. The development of molecular techniques, especially those applications based on the polymerase chain reaction (PCR), has revolutionized the diagnosis of viral infectious diseases [3,4]. Degenerate oligonucleotide primers, which allow the amplification of several possible

\footnotetext{
* Correspondence: aida@riken.jp

'Viral Infectious Diseases Unit, RIKEN, 2-1 Hirosawa, Wako, Saitama 351-0198, Japan

Full list of author information is available at the end of the article
}

mutated versions of a gene, have been successfully used for cDNA cloning and for the detection of sequences that are highly variable due to a high rate of mutation [5]. Degenerate primers are useful for the amplification of unknown genes, and also for the simultaneous amplification of similar, but not identical, genes [6]. The use of degenerate primers can significantly reduce the cost and time spent on viral detection. The "Coordination of Common Motifs" (CoCoMo) algorithm has been developed especially for the detection of multiple virus species (Endoh D, Mizutani T, Morikawa S, Hamaguchi I, Sakai K, Takizawa K, Osa Y, Asakawa M, Kon Y,
C Biomed Central

() 2010 Jimba et al; licensee BioMed Central Ltd. This is an Open Access article distributed under the terms of the Creative Commons Attribution License (http://creativecommons.org/licenses/by/2.0), which permits unrestricted use, distribution, and reproduction in any medium, provided the original work is properly cited. 
Hayashi M: CoCoMo-Primers: a web server for designing degenerate primers for virus research, submitted). This program uses an extension of the COnsensusDEgenerate Hybrid Oligonucleotide Primer (CodeHop) technique [7], which is based on multiple DNA sequence alignments using MAFFT multiple sequence alignment program [8]. The CoCoMo selects common gap tetranucleotide motifs (GTNM), which include codons from the target sequences. It then selects amplifiable sets of common GTNMs using a database-based method and constructs consensus oligonucleotides at the 5' end of each common amplifiable GTNM. The consensus degenerate sequence is then attached to the designed degenerate primers. Thus, the CoCoMo algorithm is very useful in the design of degenerate primers for highly degenerate sequences.

Bovine leukemia virus $(B L V)$ is closely related to human T-cell leukemia virus types 1 and 2 (HTLV-1 and -2) and is the etiological agent of enzootic bovine leukosis $(\mathrm{EBL})$, which is the most common neoplastic disease of cattle [9]. Infection with BLV can remain clinically silent, with cattle in an aleukemic state. It can also emerge as a persistent lymphocytosis (PL), characterized by an increased number of B lymphocytes, or more rarely, as a B-cell lymphoma in various lymph nodes after a long latent period [9].

In addition to the structural and enzymatic Gag, Pol, and Env proteins, BLV encodes at least two regulatory proteins, namely Tax and Rex, in the $\mathrm{pX}$ region located between the env gene and the 3' long terminal repeat (LTR) [9]. Moreover, BLV contains several other small open reading frames in the region between the env gene and the tax/rex genes in the $\mathrm{pX}$ region. These encode products designated as R3 and G4 [10]. BLV has two identical LTRs, which possess a U3 region, an unusually long $\mathrm{R}$ region, and a U5 region; these LTRs only exert efficient transcriptional promoter activity in cells productively infected with BLV [9]. BLV can integrate into dispersed sites within the host genome [11] and appears to be transcriptionally silent in vivo [12]. Indeed, transcription of the BLV genome in fresh tumor cells or in fresh peripheral blood mononuclear cells (PBMCs) from infected individuals is almost undetectable by conventional techniques $[12,13]$. In situ hybridization has revealed the expression of viral RNA at low levels in many cells, and at a high level in a few cells in populations of freshly isolated PBMCs from clinically normal BLV-infected animals [14]. It appears that BLV provirus remains integrated in cellular genomes, even in the absence of detectable BLV antibodies. Therefore, in addition to the routine diagnosis of BLV infection using conventional serological techniques such as the immunodiffusion test [15-18] and enzyme-linked immunosorbent assay (ELISA) [17-20], diagnostic BLV PCR techniques that aim to detect the integrated BLV proviral genome within the host genome are also commonly used [17-19,21-23]. However, real-time quantitative PCR for BLV provirus of all known variants has not been developed, largely due to differences in amplification efficiency caused by DNA sequence variations between clinical samples.

BLV infects cattle worldwide, imposing a severe economic impact on the dairy cattle industry [16-20,24-26]. Recent studies on the genetic variability of the BLV env gene have shown genetic variations among BLV isolates from different locations worldwide [24,27]. Therefore, in this study, we used the CoCoMo algorithm to design degenerate primers addressing BLV diversity and used these primers to develop a new quantitative real-time PCR method to measure the proviral load of all BLV variants. To normalize the viral genomic DNA, the BLV-CoCoMo-qPCR technique amplifies a single-copy host gene [bovine leukocyte antigen (BoLA)-DRA gene] in parallel with the viral genomic DNA. The assay is specific, sensitive, quantitative and reproducible, and is able to detect BLV strains from cattle worldwide, including those for which previous attempts at detection by nested PCR failed. Interestingly, we succeeded in confirming that the BLV copy number in PBMC clearly increased with disease progression.

\section{Results}

Principle of absolute quantification for determination of BLV proviral copy number

To determine the absolute copy number of BLV provirus, we selected the LTR region as a target sequence for PCR amplification (Figure 1A). In designing the assay, we took into account the fact that two LTRs will be detected for each individual BLV genome (see equation below). To normalize genomic DNA input, the assay also included a parallel amplification of the singlecopy BoLA-DRA gene (Figure 1B). The number of proviral copies per 100,000 cells is calculated according to the following equation:

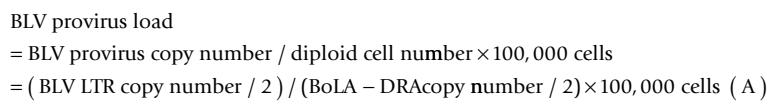

Use of the CoCoMo algorithm to construct a primer set with the ability to amplify all BLV strains

To amplify all BLV variants, primers targeting the BLV LTR region were constructed using the modified CoCoMo algorithm, which was developed to design PCR primers capable of amplifying multiple strains of virus. We collected $356 \mathrm{BLV}$ nucleotide sequences from GenBank (on 30 ${ }^{\text {th }}$ April, 2009). From these BLV sequences, 102 LTR sequences were selected according 


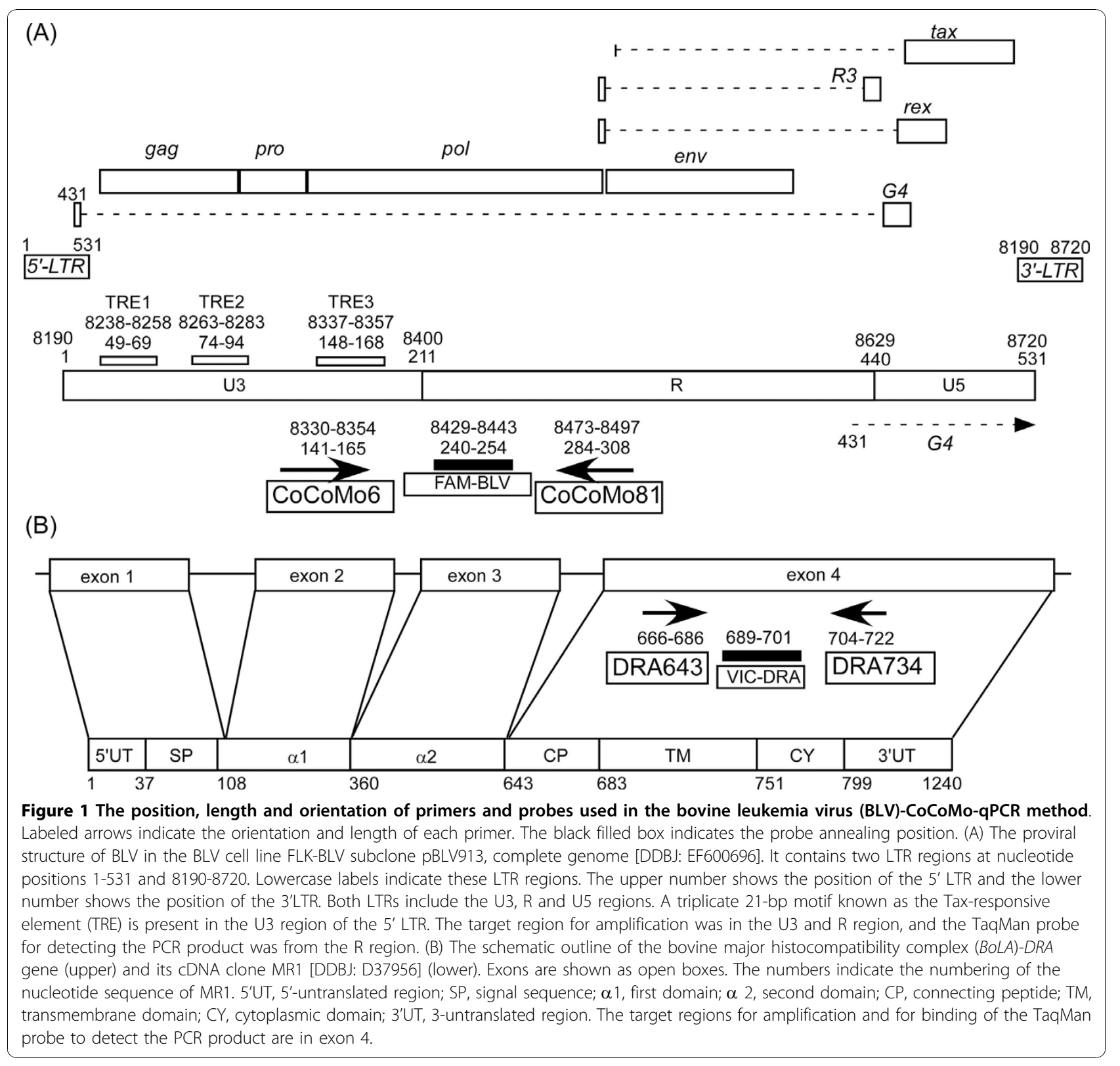

to GenBank annotations (Additional file 1). From the LTR sequences, we selected 85 sequences that were large enough to determine homologies and assigned the sequences to major BLV LTR groups based on homology using a graphical approach with Pajek graphical software (Additional file 2). Fifty two of these sequences were selected for primer design (Additional file 3). The target sequences were subjected to a BLV LTR modified version of the CoCoMo-primer-design algorithm, which was developed for designing degenerate primers to detect multiple strains of virus. Using these sequences as templates, a total of 72 primer sets (Figure 2B) with 49 candidate primers (Table 1) were designed.
Selection of the primer set and probe for amplification of the BLV LTR region

To determine whether the CoCoMo primer sets amplified the BLV LTR region, touch-down PCR was performed with 72 candidate primer sets (Figure 2B) using genomic DNA extracted from BLV-infected BLSC-KU17 cells. As shown in Figure 2A, we identified 16 sets of primers, 1-6, 9, 15-17, 20, 21, 24, 33, 43 and 46, which successfully amplified the BLV LTR region.

The specificity of the 16 selected primer sets was evaluated by melting-curve analysis of amplification using genomic DNA extracted from BLSC-KU-17 cells or PBMCs from BLV-free normal cattle Ns118, with reagent-only as the negative control. Figure $2 \mathrm{C}$ shows 


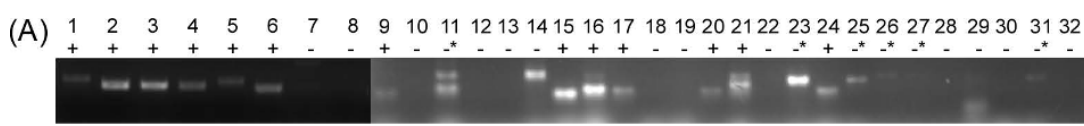

$333435363738394041424344454647484950515253545556 \quad 5758596061 \quad 62636465 \quad 66 \quad 6768 \quad 69707172$

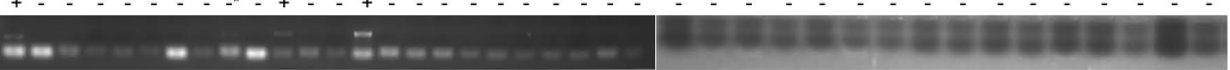

(B)

\begin{tabular}{|c|c|c|c|c|c|c|c|c|c|c|c|c|c|c|}
\hline \multirow{2}{*}{$\begin{array}{l}\text { Primer } \\
\text { set ID }\end{array}$} & \multirow{2}{*}{$\begin{array}{c}\text { Total } \\
\text { degeneracy }\end{array}$} & \multirow{2}{*}{$\begin{array}{l}\text { Size } \\
\text { (bp) }\end{array}$} & \multicolumn{2}{|c|}{ Primer ID } & \multirow{2}{*}{$\begin{array}{l}\text { Primer } \\
\text { set ID }\end{array}$} & \multirow{2}{*}{$\begin{array}{c}\text { Total } \\
\text { degeneracy }\end{array}$} & \multirow{2}{*}{$\begin{array}{l}\text { Size } \\
\text { (bp) }\end{array}$} & \multicolumn{2}{|c|}{ Primer ID } & \multirow{2}{*}{$\begin{array}{c}\text { Primer } \\
\text { set ID }\end{array}$} & \multirow{2}{*}{$\begin{array}{c}\text { Total } \\
\text { degeneracy }\end{array}$} & \multirow{2}{*}{$\begin{array}{l}\text { Size } \\
\text { (bp) }\end{array}$} & \multicolumn{2}{|c|}{ Primer ID } \\
\hline & & & $5^{\prime}$ & $3^{\prime}$ & & & & $5^{\prime}$ & $3^{\prime}$ & & & & $5^{\prime}$ & $33^{\prime}$ \\
\hline 1 & $3.1 \mathrm{E}+03$ & 140 & 1 & 73 & 25 & $7.3 \mathrm{E}+08$ & 140 & 8 & 97 & 49 & 1.3E+12 & 150 & 7 & 95 \\
\hline 2 & $3.7 E+04$ & 110 & 2 & 73 & 26 & $1.5 E+09$ & 120 & 22 & 85 & 50 & $1.5 \mathrm{E}+12$ & 160 & 33 & 97 \\
\hline 3 & $7.4 \mathrm{E}+04$ & 110 & 3 & 73 & 27 & $1.5 \mathrm{E}+09$ & 130 & 22 & 90 & 51 & $4.0 \mathrm{E}+12$ & 260 & 22 & 83 \\
\hline 4 & $2.2 E+05$ & 110 & 4 & 76 & 28 & $1.5 E+09$ & 130 & 22 & 81 & 52 & $6.7 E+12$ & 200 & 39 & 97 \\
\hline 5 & $6.6 \mathrm{E}+05$ & 130 & 5 & 73 & 29 & $2.3 \mathrm{E}+09$ & 170 & 22 & 73 & 53 & 1. $3 \mathrm{E}+13$ & 200 & 32 & 97 \\
\hline 6 & $7.9 \mathrm{E}+05$ & 100 & 6 & 76 & 30 & $2.7 E+09$ & 150 & 30 & 80 & 54 & $1.8 \mathrm{E}+13$ & 200 & 32 & 112 \\
\hline 7 & $1.8 \mathrm{E}+06$ & 110 & 7 & 76 & 31 & $2.9 \mathrm{E}+09$ & 140 & 8 & 103 & 55 & $2.7 E+13$ & 200 & 39 & 103 \\
\hline 8 & $2.7 \mathrm{E}+06$ & 130 & 8 & 80 & 32 & $3.1 \mathrm{E}+09$ & 190 & 32 & 83 & 56 & $3.6 \mathrm{E}+13$ & 150 & 22 & 108 \\
\hline 9 & $3.5 E+06$ & 130 & 4 & 81 & 33 & $5.4 \mathrm{E}+09$ & 150 & 33 & 80 & 57 & $3.6 E+13$ & 140 & 56 & 108 \\
\hline 10 & $5.3 E+06$ & 230 & 1 & 83 & 34 & $6.1 \mathrm{E}+09$ & 190 & 34 & 80 & 58 & $E+13$ & 140 & 58 & 130 \\
\hline 11 & $5.3 E+06$ & 170 & 4 & 73 & 35 & $9.2 \mathrm{E}+09$ & 260 & 4 & 83 & 5 & 5. & 200 & 32 & 103 \\
\hline 12 & 6.3 & 120 & 12 & 8 & 36 & 1.0 & 110 & 5 & 108 & 6 & 13 & 150 & 22 & 95 \\
\hline 13 & $6.3 \mathrm{E}+06$ & 110 & 12 & 85 & 37 & $1.6 \mathrm{E}+10$ & 250 & 12 & 83 & 61 & $9.5 \mathrm{E}+13$ & 260 & 12 & 112 \\
\hline 14 & $9.4 \mathrm{E}+06$ & 160 & 12 & 73 & 38 & $2.1 \mathrm{E}+10$ & 110 & 5 & 95 & 62 & 1.2E +14 & 140 & 62 & 130 \\
\hline 15 & $1.3 E+07$ & 120 & 6 & 81 & 39 & $2.4 \mathrm{E}+10$ & 190 & 39 & 80 & 63 & $1.4 \mathrm{E}+15$ & 160 & 63 & 135 \\
\hline 16 & $1.9 \mathrm{E}+07$ & 160 & 6 & 73 & 40 & $3.1 \mathrm{E}+10$ & 240 & 1 & 112 & 64 & 1.7E+15 & 120 & 64 & 136 \\
\hline 17 & $2.1 \mathrm{E}+07$ & 140 & 17 & 83 & 41 & $3.3 E+10$ & 250 & 6 & 83 & 65 & $9.6 \mathrm{E}+15$ & 180 & 65 & 137 \\
\hline 18 & $2.8 E+07$ & 130 & 7 & 90 & 42 & $4.9 E+10$ & 190 & 32 & 80 & 66 & 1.7E+16 & 140 & 66 & 138 \\
\hline 19 & $2.8 \mathrm{E}+07$ & 130 & 7 & 81 & 43 & $1.2 \mathrm{E}+11$ & 150 & 17 & 112 & 67 & $2.3 E+16$ & 270 & 22 & 112 \\
\hline 20 & $4.2 \mathrm{E}+07$ & 140 & 20 & 83 & 44 & 1.7E+11 & 150 & 4 & 95 & 68 & 1.5 & 220 & 68 & 140 \\
\hline 21 & $6.4 \mathrm{E}+07$ & 200 & 2 & 83 & 45 & $2.9 \mathrm{E}+11$ & 140 & 12 & 95 & 69 & $2.3 E+17$ & 100 & 69 & 141 \\
\hline 22 & $9.6 \mathrm{E}+07$ & 120 & 1 & 95 & 46 & 3.7E+11 & 210 & 2 & 112 & 70 & $3.7 E+18$ & 110 & 70 & 142 \\
\hline 23 & $9.6 E+07$ & 110 & 22 & 76 & 47 & $5.9 E+11$ & 140 & 6 & 95 & 71 & $4.6 \mathrm{E}+18$ & 230 & 66 & 144 \\
\hline 24 & $6.8 \mathrm{E}+08$ & 150 & 20 & 80 & 48 & $6.6 \mathrm{E}+11$ & 150 & 7 & 108 & 72 & $4.6 \mathrm{E}+18$ & 160 & 68 & 143 \\
\hline
\end{tabular}

(C)

Primer set ID3(CoCoMo3-73)

Primer set ID15(CoCoMo6-81)

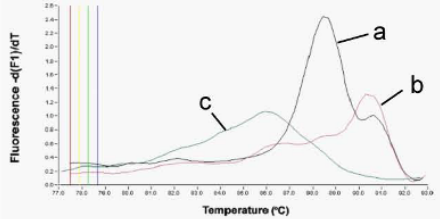

Primer set ID16(CoCoMo6-73)

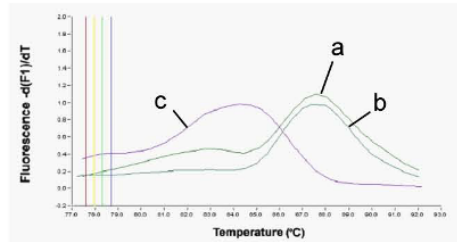

(D)

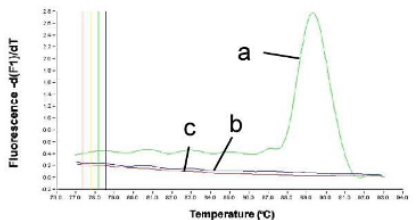

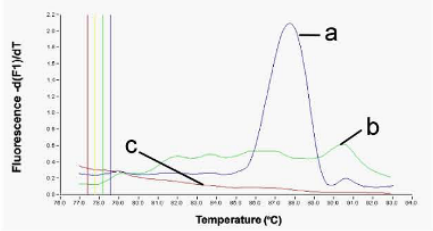

Primer set ID17(CoCoMo17-83)

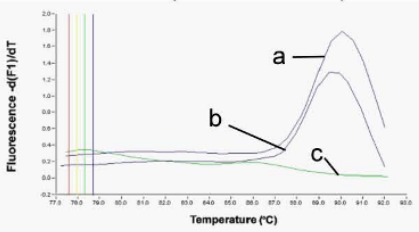

Figure 2 Selection of the primer set for amplification of the BLV LTR region. (A) Touch-down PCR was performed using 72 primer sets with 49 primers designed by the CoCoMo program as shown in Table 1. PCR products were detected by electrophoresis on a 3\% agarose gel. Lanes 1-72, 1-72 primer set ID; +, results positive for PCR product; -, negative results for same. ${ }^{*}$, designates PCR products that were detected but for which the amplicon sizes differed from the predicted size. (B) Summary of results shown in (A). Primer set IDs are arranged according to the degeneracy of the primer set and size of the PCR products. (C) The 4 representative melting curves with 16 primer sets of: BLV-infected BLSCKU-17 cells (a), BLV-free normal cattle cells (b), and reagent-only as negative control (c). The specificity of the 16 selected primer sets was checked by melting curve analysis. Each PCR amplification was followed by gradual product melting at up to $95^{\circ} \mathrm{C}$. (D) The optimization of PCR amplification with primer set ID 15 (CoCoMo 6 and 81). The melting curve of PCR products from BLV-infected BLSC-KU-17 cells (a), the BLV-free normal cattle Ns118 (b), and reagent-only as negative control (c). 
Table 1 Primer sequences for amplification of BLV LTR candidate regions by the Coordination of Common Motif (CoCoMo) algorithm

\begin{tabular}{|c|c|c|c|}
\hline \multirow[t]{2}{*}{ Primer ID } & \multirow[t]{2}{*}{ Sequence } & \multicolumn{2}{|c|}{ Primer annealing position in the BLV LTR sequence ${ }^{1}$} \\
\hline & & 3'LTR & 5'LTR \\
\hline 1 & ACCTGYYGWKAAAYTAATAMAATGC & $162-186$ & $8351-8375$ \\
\hline 2 & CYDKYSRGYTARCGGCRCCAGAAGC & $192-216$ & $8381-8405$ \\
\hline 3 & GSCCYDKYSRGYTARCGGCRCCAGA & 189-213 & $8378-8402$ \\
\hline 4 & VRRAAWHYMMNMYCYKDAGCTGCTG & $132-156$ & $8321-8345$ \\
\hline 5 & KDDWAAHTWAWWMAAWKSCGGCCCT & 169-193 & $8358-8382$ \\
\hline 6 & MNMYCYKDRSYKSYKSAYYTCACCT & $141-165$ & $8330-8354$ \\
\hline 7 & YYSVRRAAWHYMMNMYCYKDAGCTG & 129-153 & $8318-8342$ \\
\hline 8 & GCTCCCGAGRCCTTCTGGTCGGCTA & $266-290$ & $8455-8479$ \\
\hline 12 & NMYCYKDRSYKSYKSAYYTCACCTG & $142-166$ & $8331-8355$ \\
\hline 17 & SGKYCYGAGYYYKCTTGCTCCCGAG & $250-274$ & $8439-8463$ \\
\hline 20 & YSGKYCYGAGYYYKCTTGCTCCCGA & $249-273$ & $8438-8462$ \\
\hline 22 & HWRRWMHHYMMNMYSHKNWGCTGC & 130-154 & 8319-8343 \\
\hline 30 & YYYSGKYCYGAGYYYKCTTGCTCCC & $247-271$ & $8436-8460$ \\
\hline 32 & SGSMVCMRRARSBRYTCTYYTCCTG & $204-228$ & 8393-8417 \\
\hline 33 & YYYYSGKYCYGAGYYYKCTTGCTCC & $246-270$ & $8435-8459$ \\
\hline 34 & VCMRRARSBRYTCTYYTCCTGAGAC & $208-232$ & $8397-8421$ \\
\hline 39 & GSMVCMRRARSBRYTCTYYTCCTGA & $205-229$ & $8394-8418$ \\
\hline 56 & MNMYMYDNVSYKVBBBBRYYKCACCT & $141-165$ & $8330-8354$ \\
\hline 58 & YSBRRGBYBKYTYKCDSCNGAGACC & $253-277$ & $8442-8466$ \\
\hline 62 & BYSBRRGBYBKYTYKCDSCNGAGAC & $323-347$ & $8441-8465$ \\
\hline 63 & YYYYBGBYYYSWGHYYBCKYGCTCC & $246-270$ & $8587-8611$ \\
\hline 64 & VRDNYHHNHYYYBNRKYYBYTGACC & $354-378$ & $8324-8348$ \\
\hline 65 & HWNVHVNHHWNVNSNKNWGMYGS & $43-67,68-92,130-154$ & $8232-56,8257-81,8319-43$ \\
\hline 66 & NNHHDHBHRWDMMAHNSMBDSMSYK & $124-148,169-193,170-194$ & $8313-37,8358-82,8359-83$ \\
\hline 68 & BNNVBBHVNVHNYYYBNYHVMYBHS & $26-50,91-115,247-271$ & $8215-39,8280-8304,8436-60$ \\
\hline 69 & NVMNBNNHHVDNHWMHYSMBRMSCT & $123-147,128-152,211-235$ & $8312-36,8317-41,8400-24$ \\
\hline 70 & NNNBBHVBVNNHNBBRHYYBTCTCC & $202-226,360-384,375-399$ & $8391-8415,8549-73,8564-88$ \\
\hline 73 & TGGTCTCHGCYGAGARCCNCCCTCC & $325-349$ & $8514-8538$ \\
\hline 76 & GCCGACCAGAAGGYCTCGGGAGCAA & $264-288$ & 8453-8477 \\
\hline 80 & SSSRKKBWRVSCMRRMSSCCTTGG & $421-445$ & $8610-8634$ \\
\hline 81 & TACCTGMCSSCTKSCGGATAGCCGA & $284-308$ & 8473-8497 \\
\hline 83 & KKBWRVSCMRRMSSCCTTGGAGCG & $417-441$ & $8606-8630$ \\
\hline 85 & GMCSSCTKSCGGATAGCCGACCAGA & 279-303 & $8468-8492$ \\
\hline 90 & CCTGMCSSCTKSCGGATAGCCGACC & $282-306$ & $8471-8495$ \\
\hline 95 & YYYMMVMVBBKKNBTDKCCTTACCT & $304-328$ & $8493-8517$ \\
\hline 97 & RMWRDVBWGVBDSMVRSCCWKRS & $421-445,429-453$ & $8610-8634,8618-8642$ \\
\hline 103 & VMWVDRVNVSSVDKVMRVSCYWGR & $421-445,430-454$ & $8610-8634,8619-8643$ \\
\hline 108 & YYMMVMVBBKKNBTDKCCTTACCTG & $303-327$ & 8492-8516, \\
\hline 112 & WVRRNBSVRRBBWRVSCCMKWSG & $421-445,428-452$ & $8610-8634,8617-8641$ \\
\hline 130 & NKNWRVSCWWWVWKRGAGCG & $417-441,484-508$ & $8606-8630,8673-8697$ \\
\hline 135 & NNWNDRVNVBNNDKNNNNNBHNND & $4-28,90-114,105-129$, etc & 8610-8634, 8619-8643, etc \\
\hline 136 & BHYYYBNSSSVHKVSRGRKMGCCGA & 284-308, 495-519 & $8473-8497,8684-8708$ \\
\hline 137 & DRRRSYHVSVRDRSTCDSDRCCGAG & $247-271,336-360$ & $8436-8460,8525-8549$ \\
\hline 138 & WWWDSHYSSVKKSSKSWYWGCCGA & 284-308, 337-861 & $8473-8497,8526-8550$ \\
\hline 140 & NHNNNBBBSSWTRGWSKSHGCCGA & $337-361,495-519$ & $8526-8550,8684-8708$ \\
\hline 141 & NRRRVBHWWRDRSYYNSDRCCGAG & $247-271,336-360$ & $8436-8460,8525-8549$ \\
\hline 142 & NHNNNBBBSSVNYDSWSBBNGCCGA & $337-361,495-519$ & $8526-8550,8684-8708$ \\
\hline 143 & VMWVNDNNVSSVDDVMWWCYWGR & $279-303,421-445,430-454$ & $8468-8492,8610-34,8619-43$ \\
\hline 144 & WVRRNNWRDBBWWBSSMKWSG & $378-402,421-445,428-452$ & $8567-8591,8610-34,8617-41$ \\
\hline
\end{tabular}

${ }^{1}$ Numbers indicate the position in the nucleotide sequence of the FLK-BLV subclone pBLV913 [DDBJ: EF600696]. 
the four typical melting-curves. Amplicons consisting of a single PCR product with a single melting temperature exhibited a single peak, while amplicons consisting of two or more products exhibited multiple peaks. The amplicon generated using primer set ID15 of CoCoMo 6 and $\mathrm{CoCoMo} 81$ had a single melting temperature using BLSC-KU-17 genomic DNA. Using these primers, no amplicons were generated using genomic DNA from PBMCs in BLV-free normal cattle Ns118 or using the reagent-only control. In contrast, other primer sets, such as ID3, ID16 and ID17 generated amplicons from genomic DNA extracted from PBMCs from BLV-free normal cattle Ns118 or in reagent only, as well as from genomic DNA extracted from BLSC-KU-17 cells. Therefore, we proceeded to optimize the amplification conditions using primer sets CoCoMo 6 and CoCoMo 81, which were the best pair for the detection of the BLV LTR region (Figure 2D). Under these optimized conditions, amplification melting-curve analysis using genomic DNAs extracted from 56 BLV-infected cattle and from $3 \mathrm{BLV}$-free normal cattle showed the same patterns as seen in BLSC-KU-17 cells and BLV-free normal cattle Ns118 (data not shown).

The internal BLV TaqMan probe was constructed from a region of low variability located between positions corresponding to the CoCoMo 6 and CoCoMo 81 primers in the LTR regions of the BLV genome (Figure 1 ), and was labeled with carboxyfluorescein (FAM) dye, non-fluorescent quencher (NFQ) and minor groove binder (MGB) probe for enhancing the probe melting temperature. The probe was designated as FAM-BLV.

Alignments of the sequences corresponding to the primer and probe regions from the 52 BLV LTR sequences taken from GenBank are shown in Figure 3. Based on this comparison, out of the 52 sequences, 8 individual sequences corresponding to CoCoMo 6 primer and 4 individual sequences for CoCoMo 81 primer could be arranged. The alignment demonstrated that although the sequences in the probe region were sufficiently conserved to allow alignment of the BLV variants, the sequences corresponding to the CoCoMo 6 and CoCoMo 81 primers exhibited a low degree of similarity.

\section{Construction of the primer set and probe for quantification of the BoLA-DRA gene}

For normalization of the genomic DNA used as the PCR template, we designed primers and a probe for quantification of the BoLA-DRA gene (Figure 1). We obtained sequences from an MR1 cDNA clone [DDBJ: No. D37956] and selected the exon 4 region of the BoLA$D R A$ gene as the target for amplification. We designed the amplification primer set DRA643 and DRA734 and the internal BoLA-DRA TaqMan probe using the Primer

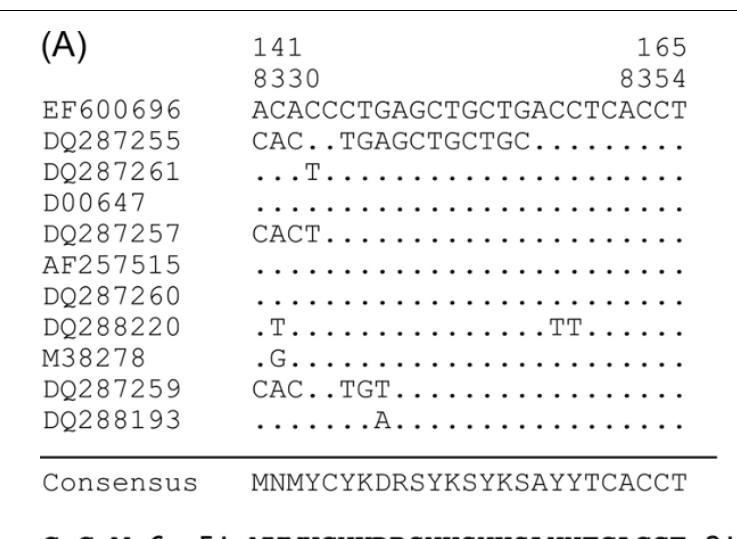

COCOMO6 5'-MNMYCYKDRSYKSYKSAYYTCACCT-3 '

(B)

EF600696

DQ287255

DQ287261

D00647

DQ287257

AF257515

DQ287260

DQ288220

M38278

DQ287259

DQ288193

\section{Consensus \\ CTCAGCTCTCGGTCC}

FAM-BLV-MGB 5 '-CTCAGCTCTCGGTCC-3'
(C)

EF600696 DQ287255

DQ287261

D00647

AF257515

DQ287260

DQ288220

M38278

DQ287259

DQ288193
DQ287257

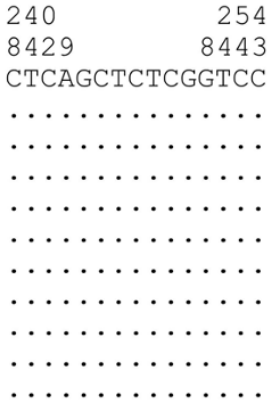

\section{Consensus TCGGCTATCCGSMAGSSGKCAGGTA}

CoCoMo81 3'-AGCCGATAGGCSKTCSSCMGTCCAT-5 '

Figure 3 Sequence alignment of annealing positions of the CoCoMo 6 primer (A), FAM-BLV-MGB probe (B) and CoCoMo 81 primer $(C)$ in the $\mathbf{5 2}$ BLV LTR sequences. The sequence alignment used 52 sequences from GenBank that were integrated into a total of 11 sequences, including 8 individual sequences for the CoCoMo 6 primer and 4 individual sequences for the CoCoMo81 primer. Accession numbers for the representative sequences are indicated in the left column. Numbers indicate the numbering of the nucleotide sequence of the FLK-BLV subclone pBLV913 [DDBJ: EF600696]. The upper number shows the position of the $5^{\prime}$ LTR and the lower number shows the position of the $3^{\prime}$ LTR. 
Express 3.0 (Applied Biosystems, Tokyo, Japan). The probe was labeled with VIC dye, NFQ and an MGB probe for enhancing the probe melting temperature, and was designated as VIC-DRA.

\section{Quantification of plasmid DNA copy number to create standard curves for absolute quantitative PCR}

To obtain standards for quantification of BLV proviral DNA and cellular DNA, pBLV-LTR/SK, which includes a full-length LTR of BLV, and pBoLA-DRA/SK, which includes a full-length bovine $D R A$ gene, were prepared at $103.1 \mathrm{ng} / \mu \mathrm{l}\left(\mathrm{pBLV}-\mathrm{LTR}^{\mathrm{conc}}\right.$ ) and $125.0 \mathrm{ng} / \mu \mathrm{l}$ (pBoLA$\left.\mathrm{DRA}^{\text {conc }}\right)$, respectively. The copy numbers of these plasmids were calculated by the serial dilution method: each plasmid was diluted 10-fold, and the target DNA was detected by nested PCR. For example, at a $10^{-11}$ dilution of $\mathrm{pBLV}-\mathrm{LTR}^{\mathrm{conc}}$, PCR amplification failed to detect any PCR product, including the BLV LTR. The PCR reaction was then replicated 10 times at the $10^{-11}$ dilution, and the success rate was found to be $5 / 10$. This result showed that 5 of 10 PCR solutions did not contain the LTR gene, expressed in equation form as: $f(x=0)=5 /$ 10 . Finally, the average copy number of the target gene $(\lambda)$ was calculated as $-\log _{\mathrm{e}}(5 / 10)=0.231$ corresponding to a copy number for pBLV-LTR ${ }^{\text {conc }}$ of $2.31 \times 10^{10} / \mu \mathrm{l}$. Using the same strategy, the copy number of pBoLA$\mathrm{DRA}^{\text {conc }}$ was determined to be $2.54 \times 10^{10} / \mu \mathrm{l}$. For confirmation of the reliability of estimated copy numbers, we also calculated draft copy numbers from the DNA weight and obtained a very similar result $\left(2.35 \times 10^{10}\right.$ for $\mathrm{pBLV}-\mathrm{LTR}^{\mathrm{conc}}$, and $2.85 \times 10^{10}$ for pBoLA-DRA $\left.{ }^{\text {conc }}\right)$.

\section{Final procedure for the optimization of BLV-CoCoMo- qPCR}

To construct the standard curve, the following dilutions of pBLV-LTR ${ }^{\text {conc }}$ and pBoLA-DRA ${ }^{\text {conc }}$ were created: 0.1 copy/ $\mu \mathrm{l}, 1$ copy/ $\mu \mathrm{l}, 1,000$ copies/ $\mu \mathrm{l}$ and 1,000,000 copies/ $\mu$ l. A 168-bp amplicon from the BLV LTR region was amplified in a total volume of $20 \mu \mathrm{l}$ of $1 \times$ TaqMan Gene Expression Master Mix containing $500 \mathrm{nM}$ CoCoMo 6 primer, $50 \mathrm{nM}$ CoCoMo 81 primer, $150 \mathrm{nM}$ FAM-BLV probe (5'-FAM-CTCAGCTCTCGGTCCNFQ-MGB-3'), and $30 \mathrm{ng}$ of template DNA. In addition, a 57-bp amplicon of the $B o L A-D R A$ region was amplified in a total volume of $20 \mu$ of $1 \times$ TaqMan Gene Expression Master Mix containing $50 \mathrm{nM}$ of DRA643 primer (5'-CCCAGAGACCACAGAGAATGC-3'), 50 nM of DRA734 primer (5'-CCCACCAGAGCCACAATCA-3'), $150 \mathrm{nM}$ of VIC-DRA probe (5'-VICTGTGTGCCCTGGGC-NFQ-MGB 3'), and $30 \mathrm{ng}$ of template DNA. PCR amplification was performed with the ABI 7500 Fast Real-time PCR system according to the following program: Uracil-DNA Glycosylase (UDG) enzyme activation at $50^{\circ} \mathrm{C}$ for 2 min followed by
AmpliTaq Gold Ultra Pure (UP) enzyme activation at $95^{\circ} \mathrm{C}$ for $10 \mathrm{~min}$, and then 85 cycles of $15 \mathrm{sec}$ at $95^{\circ} \mathrm{C}$ and $1 \mathrm{~min}$ at $60^{\circ} \mathrm{C}$. Copy numbers obtained for the BLV LTR and BoLA-DRA were used to calculate BLV proviral load per 100,000 cells, as shown in Equation (A).

\section{Reproducibility of BLV-CoCoMo-qPCR}

The intra- and inter-assay reproducibility of BLVCoCoMo-qPCR for determination of BLV proviral copy number was evaluated using aliquots of genomic DNA extracted from blood samples from seven BLV-infected cattle (Table 2). For determination of intra-assay reproducibility, we examined triplicate PCR amplifications from each sample, with the assay being repeated three times. A total of 21 examinations were performed, and the intra-assay coefficient of variance $(\mathrm{CV})$ ranged from $0 \%$ to $20.5 \%$ (mean $8.6 \%$ ). For determination of interassay reproducibility, we performed three independent experiments for each sample. The values for the interassay CV for BLV proviral copy number per 100,000 cells ranged from $5.5 \%$ to $19.8 \%$ (mean $12.7 \%$ ). These results clearly demonstrated that this assay has good intra- and inter-assay reproducibility.

\section{Evaluation of the specificity of BLV-CoCoMo-qPCR primers using various retroviruses}

The specificity of BLV-CoCoMo-qPCR primers was tested using various retroviral molecular clones, including BLV, HTLV-1, human immunodeficiency virus type 1 (HIV-1), simian immunodeficiency virus (SIV), mouse mammary tumor virus (MMTV), Molony murine leukemia virus (M-MLV), and a range of plasmids including pUC18, pUC19, pBR322, and pBluescript II SK (+). For real-time PCR, CoCoMo 6 and CoCoMo 81 primers were used with $0.3 \mathrm{ng}$ of each plasmid, and the products were analyzed by $3 \%$ agarose-gel electrophoresis. A single PCR product, 168-bp in length, was observed only for the BLV infectious molecular clone (Figure 4A), with a copy number of $7.9 \times 10^{10} / \mu \mathrm{g} \pm 4.3 \times 10^{10} / \mu \mathrm{g}$ (Figure $4 B)$. No amplicons were detected for any of the other plasmids. These results strongly indicate that BLVCoCoMo-qPCR primers specifically amplify the BLV LTR without amplifying the LTRs of other retroviruses.

\section{Evaluation of the sensitivity of BLV-CoCoMo-qPCR compared with nested PCR}

To determine the sensitivity of BLV-CoCoMo-qPCR, 20 solutions, each containing 0.7 copies of pBLV-LTR/SK, were amplified by nested PCR and real-time PCR using the CoCoMo 6 and CoCoMo 81 primer set (Figure 5). Three out of ten nested PCR amplifications were positive, and the copy number was estimated to be 0.36 . For real-time PCR using the CoCoMo 6 and CoCoMo 81 primer set, five out of ten PCR amplifications were 
Table 2 Intra- and inter-assay reproducibility of BLV-CoCoMo-qPCR

\begin{tabular}{|c|c|c|c|c|c|c|c|}
\hline \multirow[t]{2}{*}{ No. } & \multicolumn{3}{|c|}{ Proviral load $^{1}$} & \multicolumn{3}{|c|}{ Intra-assay ${ }^{2}$} & \multirow{2}{*}{$\frac{\text { Inter-assay }}{\text { Exp.1 3 }}$} \\
\hline & Exp.1 & Exp 2 & Exp 3 & Exp.1 & Exp.2 & Exp.3 & \\
\hline Ns105 & $1998 \pm 385$ & $2107 \pm 296$ & $1581 \pm 150$ & 17.9 & 14.1 & 9.5 & 14.6 \\
\hline Ns209 & $3951 \pm 691$ & $3751 \pm 529$ & $3049 \pm 150$ & 17.5 & 14.1 & 4.9 & 13.2 \\
\hline Ns126 & $20388 \pm 222$ & $23484 \pm 1854$ & $28375 \pm 1381$ & 1.1 & 7.9 & 4.9 & 16.7 \\
\hline Ns226 & $30155 \pm 6184$ & $27247 \pm 1454$ & $34954 \pm 3021$ & 20.5 & 5.3 & 8.6 & 12.6 \\
\hline Ns120 & $57236 \pm 6127$ & $59375 \pm 3195$ & $53225 \pm 2514$ & 10.7 & 5.4 & 4.7 & 5.5 \\
\hline Ns107 & $90947 \pm 0$ & $73002 \pm 3228$ & $61388 \pm 4779$ & 0.0 & 4.4 & 7.8 & 19.8 \\
\hline Ns112 & $87377 \pm 7434$ & $94934 \pm 5891$ & $84667 \pm 5763$ & 8.5 & 6.2 & 6.8 & 6.0 \\
\hline
\end{tabular}

${ }^{1}$ Values represent the mean \pm standard deviation (SD) of BLV proviral copy numbers in $10^{5}$ cells from triplicate PCR amplifications from each sample.

${ }^{2}$ Intra-CV: Coefficient of variation between each sample.

${ }^{3}$ Inter-CV: Coefficient of variation between each experiment.

positive, and the copy number was estimated to be 0.69 . This result showed that the sensitivity of BLV-CoCoMoqPCR was 1.9-fold greater than that of nested PCR.

\section{Comparison of BLV-CoCoMo-qPCR and Serial dilution nested PCR}

The serial dilution method is effective for quantifying the copy number of a target gene. The BLV proviral copy number per $1 \mu \mathrm{g}$ of genomic DNA was calculated for five BLV-infected cattle by serial dilution-nested PCR and real-time PCR with the CoCoMo 6 and CoCoMo 81 primer set (Figure 6A). The BLV proviral copy number obtained by both methods was confirmed by regression analysis: the square of the correlation coefficient $\left(R^{2}\right)$ was 0.8806 (Figure $6 \mathrm{~B}$ ), indicating that the copy number obtained by real-time PCR with the CoCoMo primers correlated with that obtained by serial dilution-nested PCR. Thus, it appears that real-time PCR with the CoCoMo 6 and CoCoMo 81 primer set can be used to obtain the copy number of BLV provirus from a clinical sample.

\section{Correlation of BLV-CoCoMo-qPCR and syncytium formation assay}

To test whether the BLV proviral copy number correlates with the capacity for infection with BLV, BLVCoCoMo-qPCR and a syncytium formation assay were conducted on samples from five BLV-infected cattle. We evaluated the capacity for transmission of BLV by coculturing $1 \times 10^{5}$ PBMCs from five BLV-infected cattle with inducer CC81 cells for three days and comparing proviral copy numbers with $1 \times 10^{5}$ cells from the same cattle (Figure 7A). Proviral copy numbers ranged from 113 to 63,908 copies per $10^{5}$ cells, and syncytium numbers ranged from 36 to 12,737 per $10^{5}$ PBMCs. Regression analysis for these samples revealed that the level of provirus load positively correlated with the number of syncytia $\left(R^{2}=0.9658\right)$, as shown in Figure 7B.
BLV provirus detection in cattle from different geographic locations by BLV-CoCoMo-qPCR and nested PCR

BLV-CoCoMo-qPCR has the potential ability to detect various BLV strains, both known and unknown, because degenerate primers are capable of detecting highly degenerate sequences. In the experiments described above, we found that the sensitivity of BLV-CoCoMoqPCR was greater than that of nested PCR. Therefore, we examined whether BLV-CoCoMo-qPCR can detect BLV provirus in cattle from different geographic locations worldwide. We tested 54 cattle from one farm in Japan, 15 cattle from two farms in Peru, 60 cattle from four farms in Bolivia, 32 cattle from three farms in Chile and 5 cattle from one farm in the U.S.A., and compared the results obtained by BLV-CoCoMo-qPCR with the results obtained by nested PCR (Table 3 ). The amplification of BLV LTR by the two methods divided the 166 cattle into three groups. The first group of cattle ( $\mathrm{n}=107$ ) was positive for BLV LTR by both methods (50 in Japan, 7 in Peru, 27 in Bolivia, 18 in Chile, and 5 in U. S. A.). The second group of cattle $(n=50)$ was negative for BLV LTR by both methods (2 in Japan, 7 in Peru, 28 in Bolivia, and 13 in Chile). The third group of cattle $(n=9)$ was positive by BLV-CoCoMo-qPCR but negative by nested PCR ( 2 in Japan, 1 in Peru, 5 in Bolivia, and 1 in Chile). Interestingly, none of the cattle were negative by BLV-CoCoMo-qPCR but positive by nested PCR. Thus, the nested PCR and BLV-CoCoMoqPCR methods gave the same result for $94.6 \%$ of the cattle tested, but for $5.4 \%$ of the cattle, only the BLVCoCoMo-qPCR was able to detect BLV provirus. These results clearly showed that the sensitivity of BLVCoCoMo-qPCR was higher than that of nested PCR.

As shown in Table 3, we detected several samples that were positive by BLV-CoCoMo-qPCR, but negative by nested PCR. To confirm that these samples were infected with BLV, and to investigate why these samples were not detected by nested PCR, we sequenced the LTR region of nine samples from this group: YA40, 


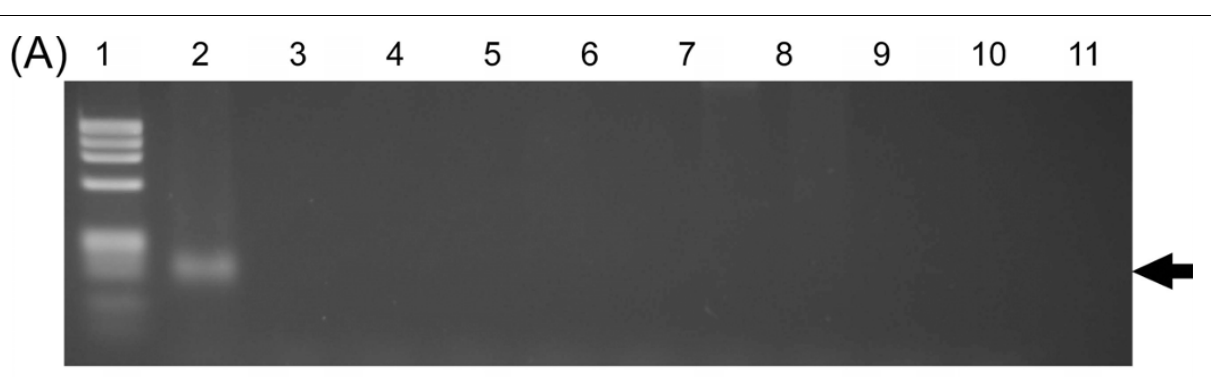

(B)

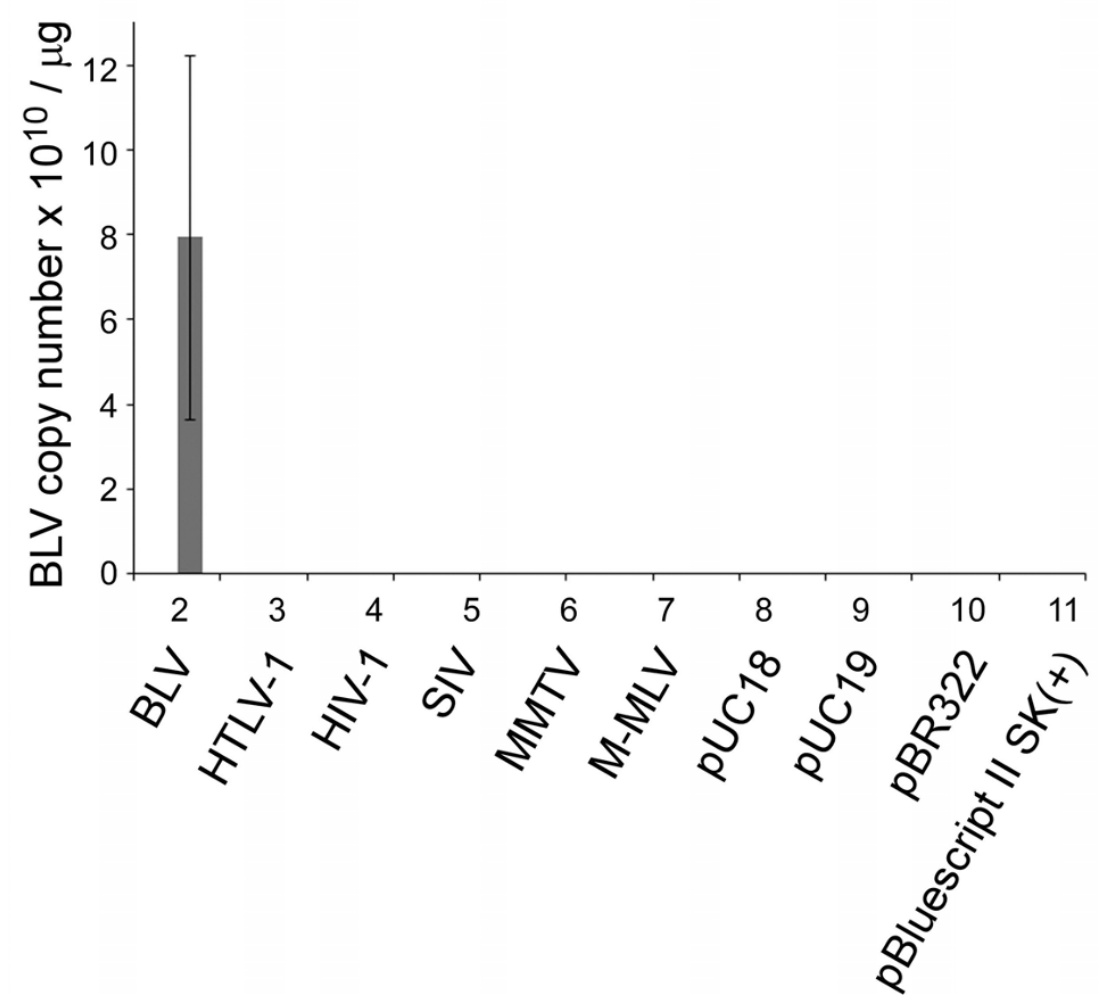

Figure 4 Evaluation of the specificity of the BLV-CoCoMo-qPCR primers. (A) Real-time PCR using the CoCoMo 6 and CoCoMo 81 primers from the BLV-CoCoMo-qPCR was performed using 0.3 ng of the following infectious molecular clones: BLV (pBLV-IF, lane 2); HTLV-1 (pK30, lane 3); HIV-1 (pNL4-3, lane 4); SIV (pSIVmac239/NT, lane 5); MMTV (hybrid MMTV, lane 6); M-MLV (pL-4, lane 7); and the plasmids pUC18 (lane 8), pUC19 (lane 9), pBR322 (lane 10), and pBluescript SK(+) (lane 11). PCR products were subjected to 3\% agarose gel electrophoresis. Lane 1, DNA marker $\Phi \times 174$-Hae III digest. A PCR product 168 bp in length is indicated by an arrow. (B) The number of BLV provirus copies in $1 \mu \mathrm{\mu g}$ of DNA from each DNA sample is indicated by lowercase. Values represent the mean \pm standard deviation (SD) of the results of three independent experiments.

MO85, YA35, YA56 and ME10 from Bolivia, HY2 from Peru, C336 from Chile, and Ns27 and Ns29 from Japan. We were able to detect BLV LTR sequences in all nine samples (Figure 8), thus confirming the high specificity of BLV-CoCoMo-qPCR. In two of the nine samples, we identified mismatch sequences at the annealing region for the primer BLTR453, which was used for amplification of the LTR in nested PCR. This is a possible explanation for why the nested PCR failed to detect the BLV provirus.

\section{Correlation analysis of disease progression and BLV proviral load}

To characterize differences in BLV proviral load in the early and late stages of disease, we calculated BLV proviral copy numbers for 268 BLV-infected cattle in different stages of progression of EBL. We measured proviral load in 163 BLV-positive, healthy cattle, 16 BLV-infected cattle with PL, $89 \mathrm{BLV}$-infected cattle with lymphoma, and 117 BLV-free normal cattle by BLV-CoCoMo-qPCR (Figure 9). The proviral loads were significantly 


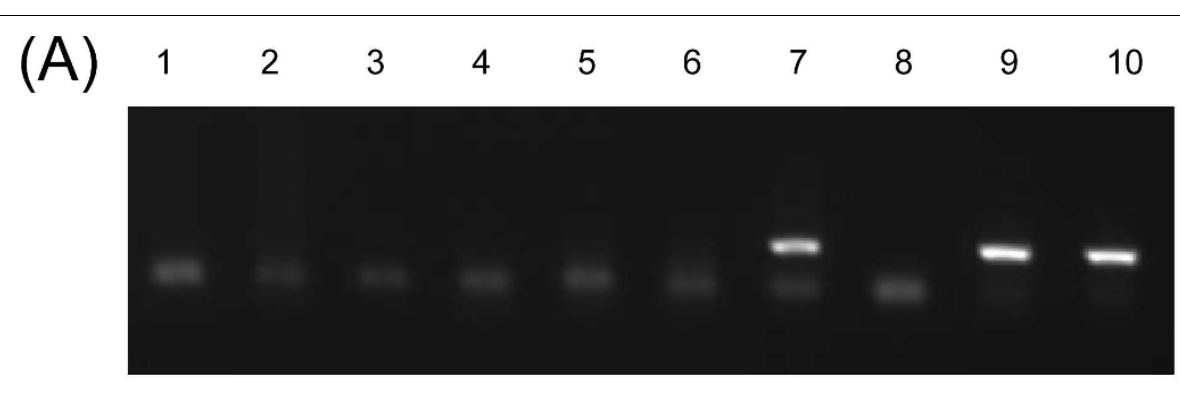

(B)

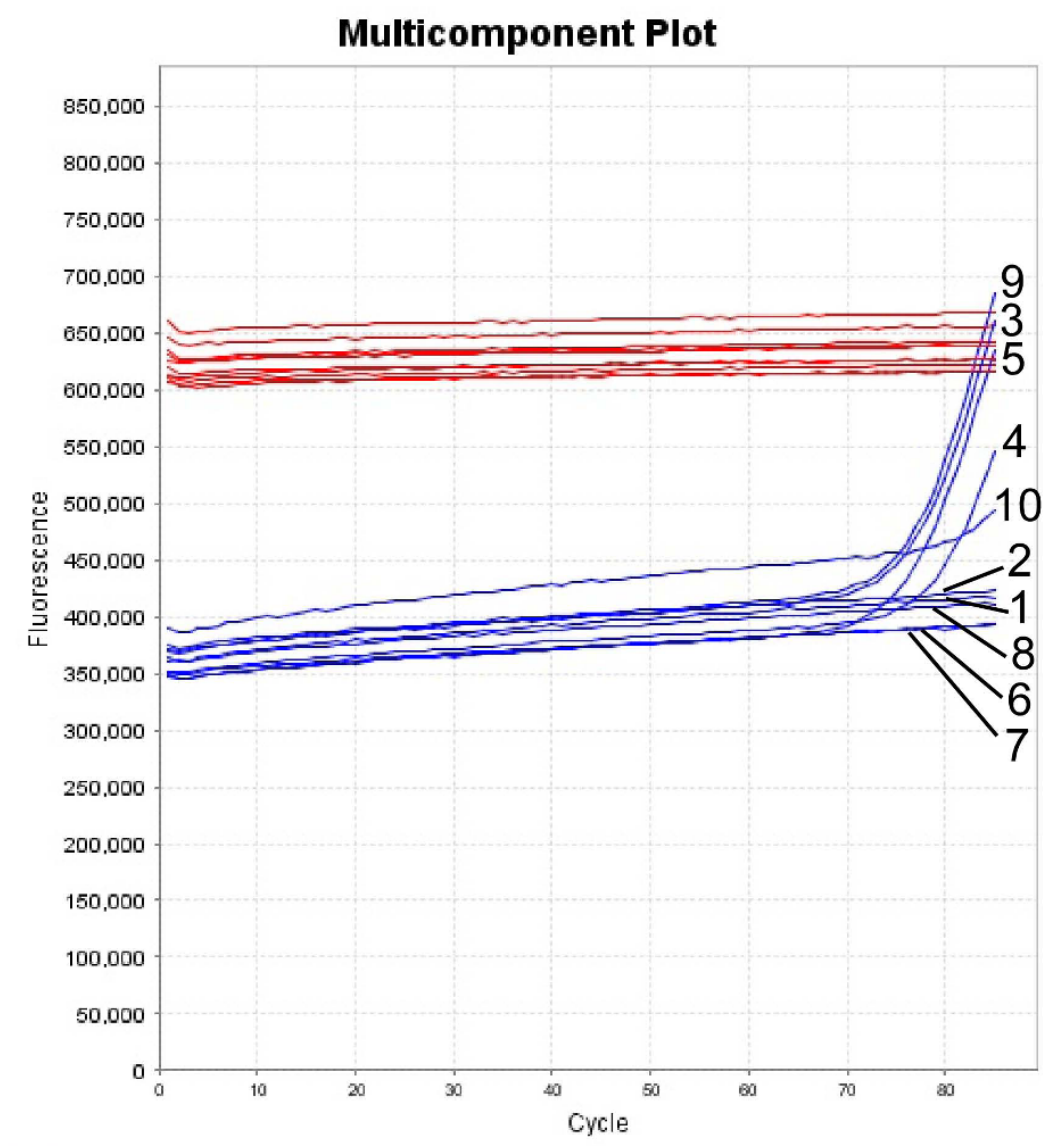

\section{ROX $\square$ FAM}

Figure 5 Comparison of the sensitivity of BLV-CoCoMo-qPCR and nested PCR. Ten samples containing 0.7 copies of pBLV-LTR/SK were amplified by nested PCR (A) and real-time PCR with the CoCoMo 6 and CoCoMo 81 primer set (B). The 168-bp band was used to detect BLV LTR amplicons (A). Carboxy-X-rhodamine (ROX) intensities were used for corrections of tube differences, and carboxyfluorescein (FAM) intensities were used to detect BLV LTR amplicons (B). 


\begin{tabular}{|c|c|c|}
\hline \multirow[b]{2}{*}{ Sample No. } & \multicolumn{2}{|c|}{ BLV proviral load (copies $/ 1 \mu \mathrm{gDNA}$ ) } \\
\hline & BLV-CoCoMo-qPCR & Serial dilution-Nested PCR \\
\hline Ns103 & $274,331 \pm 135,773$ & 52,680 \\
\hline Ns126 & $1,117,540 \pm 513,636$ & 111,572 \\
\hline Ns120 & $5,869,600 \pm 770,290$ & 601,986 \\
\hline Ns209 & $6,276,465 \pm 897,776$ & $1,115,718$ \\
\hline Ns121 & $8,366,379 \pm 563,820$ & $1,115,718$ \\
\hline Ns107 & $11,580,192 \pm 607,224$ & $2,554,128$ \\
\hline
\end{tabular}

(B)

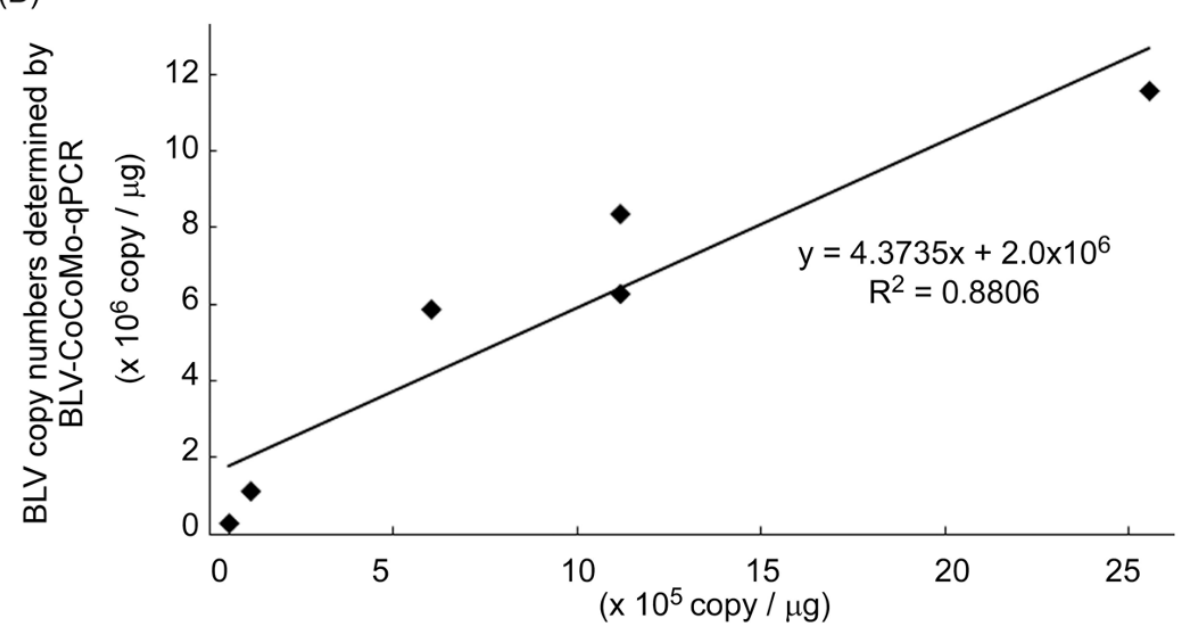

BLV copy numbers determined by serial dilution method

Figure 6 Correlation between proviral load calculated by BLV-CoCoMo-qPCR and serial dilution nested PCR. (A) BLV proviral Copy numbers for $1 \mu \mathrm{g}$ of genomic DNA from 6 BLV-infected cattle were determined by BLV-CoCoMo-qPCR and serial dilution-nested PCR. For serial dilution-nested PCR, the 6 genomic DNAs were analyzed by serial tenfold dilution and subjected to nested PCR for detection of the BLV LTR gene. Nested PCR reactions were repeated 10 times and proviral load was calculated according to a Poisson distribution model as shown in Methods. Values represent the mean \pm standard deviation (SD) of results from four independent experiments. (B) Scatter chart is indicated the correlation between BLV copy numbers which were determined by BLV-CoCoMo-qPCR and by serial dilution-nested PCR.

increased at the PL stage compared with the aleukemic stage $(\mathrm{p}=0.0159)$ and were further increased at the lymphoma stage ( $\mathrm{p}=0.0052)$. No BLV was detected in the $117 \mathrm{BLV}$-free normal cattle. Thus, we were able to demonstrate that BLV proviral copy number increased with increasing severity of disease.

\section{Discussion}

In this study, we describe the successful development of a highly specific, accurate, and sensitive method for the quantification of BLV proviral load from infected animals.

The BLV-CoCoMo-qPCR system is able to detect various BLV strains from a broad geographical origin, including Japan, Peru, Bolivia, Chile and the U.S.A. Although early studies on genetic variability of the BLV env gene identified very little variation among isolates [28], recent studies based on restriction fragment length polymorphism analysis and on analysis of the full-length BLV env gene have revealed at least seven different BLV genotypes in circulation worldwide $[24,27,29]$. This novel classification suggests that BLV divergence has increased worldwide. From a total of 356 BLV sequences in GenBank, we were able to obtain 52 distinct BLV LTR nucleotide sequences. This indicates that many BLV variants exist, and our results suggest that detection of all of these variants is possible using BLVCoCoMo-qPCR. Thus, we have clearly demonstrated that the CoCoMo algorithm is a useful tool for designing degenerate primers corresponding to multiple BLV variants. In fact, Tong et al. [30] indicated that seminested or nested PCR assays with consensus-degenerate hybrid oligonucleotide primers for Paramyxoviridae could be developed to be either highly specific or more broadly inclusive, enabling targeting at the subfamily or genus level. Using this type of approach, there is a risk 


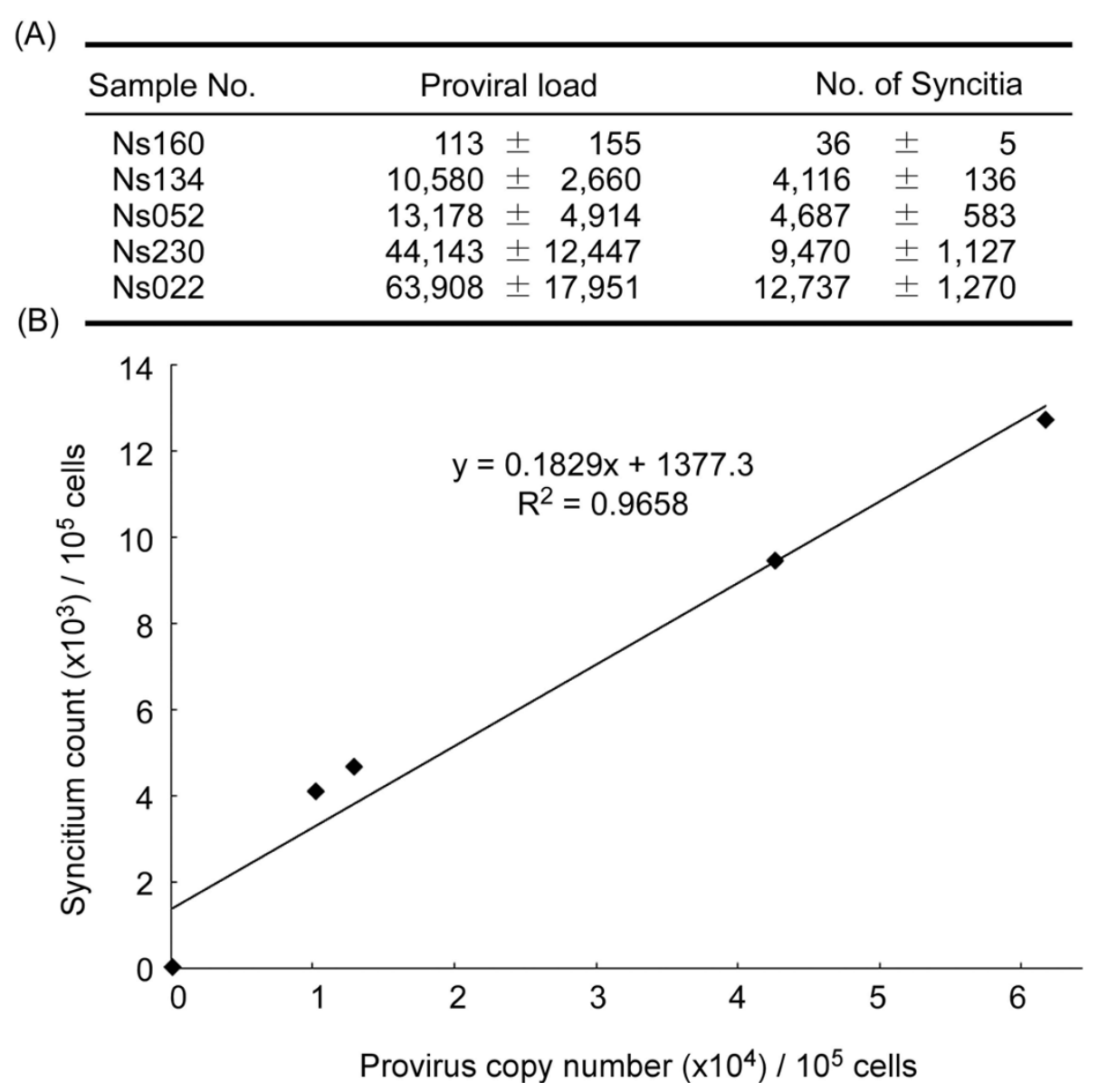

Figure 7 Correlation between proviral load calculated by BLV-CoCoMo-qPCR and syncytium formation. (A) Using BLV-CoCoMo-qPCR, the proviral loads from five BLV-infected cattle were calculated and shown as provirus copy number per $1 \times 10^{5}$ cells. A syncytium formation assay using CC81 indicator cells was used to count the number of syncytia per $1 \times 10^{5}$ peripheral blood mononuclear cells (PBMCs) from five BLVinfected cattle. Values represent the mean \pm standard deviation (SD) of results from three samples. (B) Scatter chart is indicated the correlation between BLV copy numbers which were determined by BLV-CoCoMo-qPCR and the number of syncytia.

Table 3 Comparison of BLV detection by BLV-CoCoMo-qPCR and nested PCR in cattle from Japan, Peru, Bolivia, Chile and the U.S.A.

\begin{tabular}{|c|c|c|c|c|c|c|c|c|c|c|}
\hline \multirow{3}{*}{ Country } & & \multicolumn{9}{|c|}{ Results of BLV detection by BLV-CoCoMo-qPCR/nested PCR } \\
\hline & & \multicolumn{2}{|c|}{$+/+^{1}$} & \multicolumn{2}{|c|}{$-/-$} & \multicolumn{2}{|c|}{$+/-$} & \multicolumn{2}{|c|}{$-/+$} & \multirow[b]{2}{*}{ Total number } \\
\hline & & $\mathrm{n}^{2}$ & $\%$ & $\mathbf{n}$ & $\%$ & $\mathbf{n}$ & $\%$ & $\mathbf{n}$ & $\%$ & \\
\hline Japan & A & 50 & 92.6 & 2 & 3.7 & 2 & 3.7 & 0 & 0 & 54 \\
\hline \multirow[t]{2}{*}{ Peru } & A & 7 & 77.8 & 2 & 22.2 & 0 & 0 & 0 & 0 & 9 \\
\hline & B & 0 & 0 & 5 & 83.3 & 1 & 16.7 & 0 & 0 & 6 \\
\hline \multirow[t]{4}{*}{ Bolivia } & A & 2 & 40.0 & 2 & 40.0 & 1 & 20.0 & 0 & 0 & 5 \\
\hline & B & 4 & 66.7 & 2 & 33.3 & 0 & 0 & 0 & 0 & 6 \\
\hline & C & 5 & 35.7 & 8 & 57.1 & 1 & 7.1 & 0 & 0 & 14 \\
\hline & D & 16 & 45.7 & 16 & 45.7 & 3 & 8.6 & 0 & 0 & 35 \\
\hline \multirow[t]{3}{*}{ Chile } & A & 11 & 68.8 & 4 & 25.0 & 1 & 6.2 & 0 & 0 & 16 \\
\hline & B & 0 & 0 & 6 & 100.0 & 0 & 0 & 0 & 0 & 6 \\
\hline & C & 7 & 70.0 & 3 & 30.0 & 0 & 0 & 0 & 0 & 10 \\
\hline USA & A & 5 & 100.0 & 0 & 0 & 0 & 0 & 0 & 0 & 5 \\
\hline
\end{tabular}

${ }^{1}+$, positive for detection of BLV; - negative for detection of BLV.

${ }^{2} n$, number of samples with identical decisions based on two methods. 


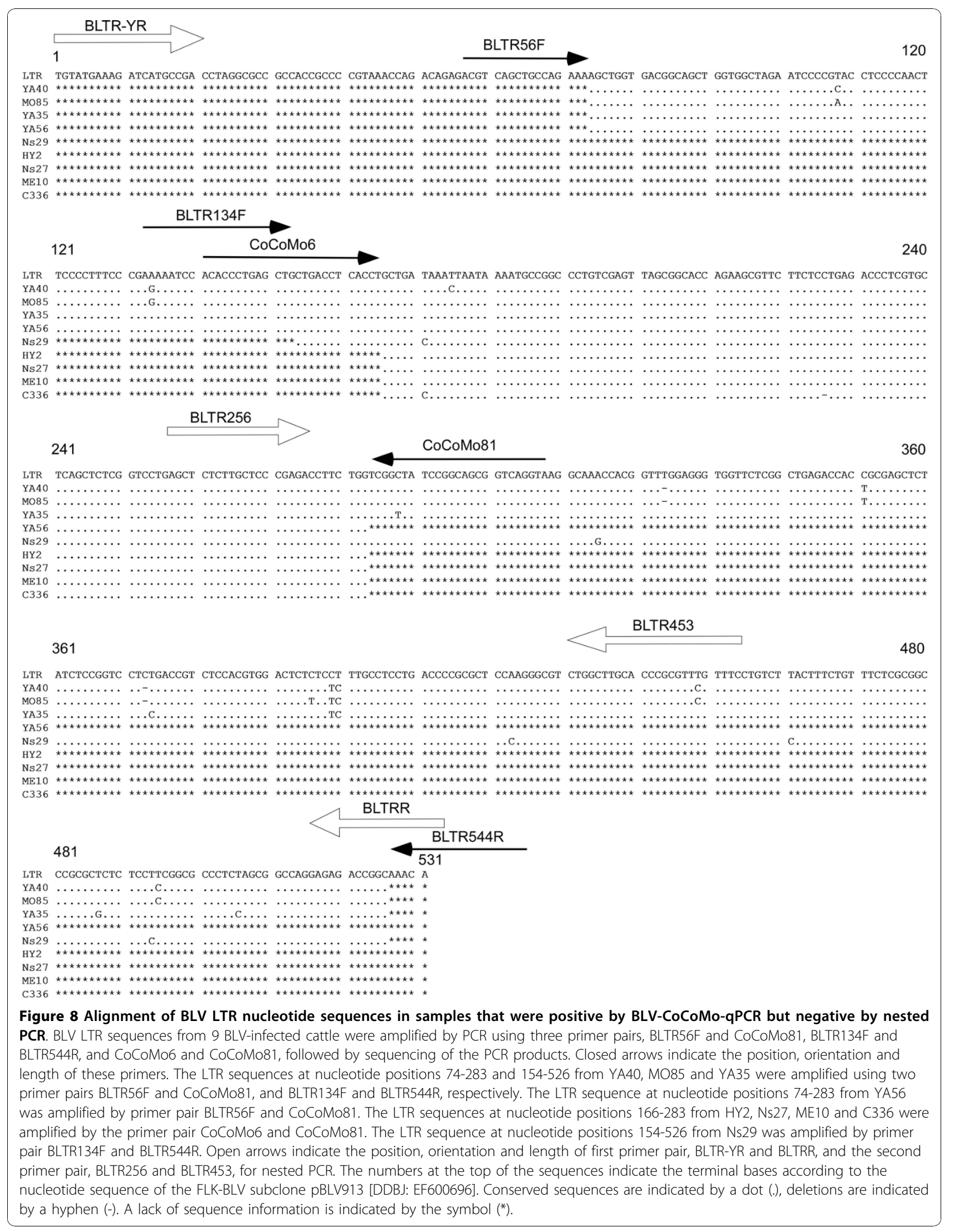




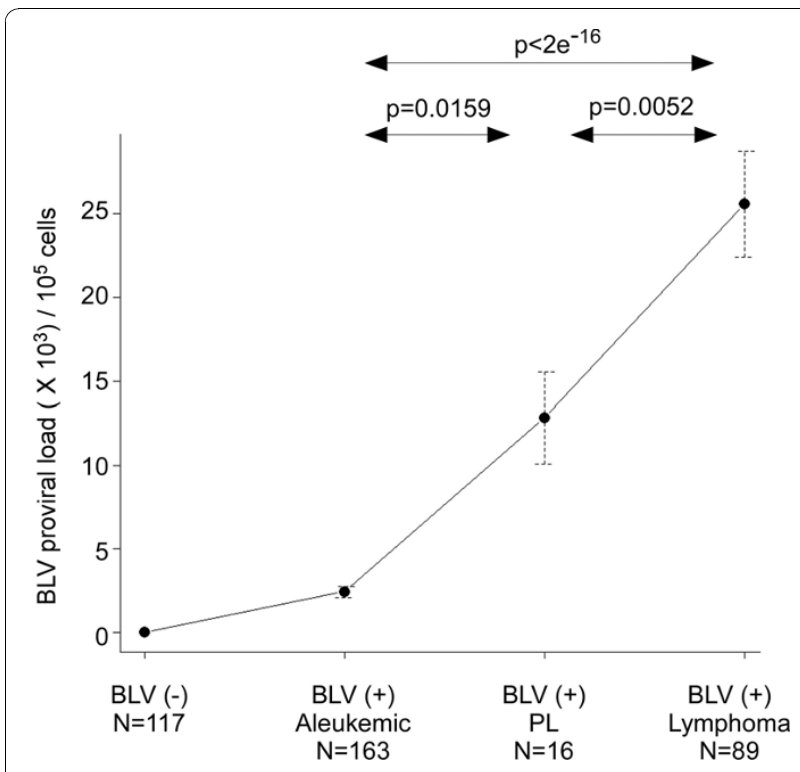

Figure 9 Increased proviral load correlates with disease progression in BLV-induced enzootic bovine leukosis (EBL). The proviral load was calculated for 385 cattle by BLV-CoCoMo-qPCR. The cattle were classified into four disease stages according to diagnosis based on previously established criteria [41], the genomic integration of BLV, and the detection of antibodies to BLV: 117 BLVnegative cattle (BLV-); 163 BLV-infected cattle that were clinically and hematologically normal (aleukemic); 16 clinically normal, BLVinfected cattle with persistent lymphocytosis (PL); and 89 BLVinfected cattle with lymphoma. The circles/dots indicate the average proviral load detected in each stage, and the bar indicates the standard error. P-values were calculated by pairwise t-test using $\mathrm{R}$ version 2.10.1 (The R Foundation for Statistical Computing).

that the degeneracy of the CoCoMo primers could be too high, thereby reducing the concentration of primer specific to the target sequence and decreasing the assay's sensitivity. This issue did not arise in our study since BLV-CoCoMo-qPCR was highly sensitive and gave superior results to nested PCR amplification (Figure 6). In addition, the BLV-CoCoMo-qPCR system was very effective in detecting virus in BLV-infected cattle from a range of geographic locations (Table 3). The TaqMan probe was used to improve sensitivity and specificity and acts to counter any drawbacks associated with high degeneracy. It is important to note that the sequence of the BLV TaqMan probe, located between positions corresponding to the CoCoMo 6 and CoCoMo 81 primers, was completely conserved among the $52 \mathrm{BLV}$ variants. The ELISA and immunodiffusion screening methods for BLV in cattle are also highly sensitive but they act by detecting antibodies against BLV, in contrast to the direct detection of integrated provirus by PCR [17]. The ELISA and immunodiffusion methods suffer from a high rate of false positives, and they are also ineffective in determining whether calves are infected since circulating maternal antibodies from BLV-infected dams can interfere with the assay. Reliable detection of BLV-infection in cattle therefore requires a high-sensitivity method for the detection of provirus. To this end, we developed BLV-CoCoMo-qPCR.

Several approaches were used to confirm the high specificity of BLV quantification using CoCoMo primers. First, the CoCoMo 6 and CoCoMo 81 primers yielded a single peak by melting curve analysis in cells infected with BLV, but did not amplify a product in uninfected cells or in the reagent-only negative control. Second, PCR amplification was detected in BLV-positive cattle, but was negative in all $120 \mathrm{BLV}$-negative cattle tested. Third, infectious molecular clones including several non-BLV retroviral LTRs were not amplified by our system.

A previous study [31] reported a method to quantify BLV provirus using real-time PCR. This method targeted the BLV env and pol genes, which are present at only one copy per provirus, and the primer annealing regions were potentially susceptible to mutation. The BLV LTR target of BLV-CoCoMo-qPCR is present at two copies per provirus, which contributes to the improved sensitivity of our assay. Indeed, using the quantitative PCR method described by Lew et al. [31], we could not detect provirus at less than 18 copies $/ 10^{5}$ cells, a concentration that was readily detectable by BLV-CoCoMo-qPCR (data not shown). Our method also has the advantage that the use of degenerate primers allows for the detection of BLV sequence variants, including those that arise from mutations.

The BLV-CoCoMo-qPCR method was also accurate. The provirus copy number obtained using real-time PCR with CoCoMo primers correlated closely with the result from serial dilution nested PCR. Because we aimed to use BLV-CoCoMo-qPCR to quantify cellassociated BLV provirus, we performed a parallel quantitation of the single-copy cellular gene BoLA-DRA. This measurement allowed adjustment for variations in amplification efficiency between samples. Using this strategy, we observed sufficient intra- and inter-assay reproducibility for the diagnosis of infected animals. The assay CV range was $0.0 \%$ to $20.5 \%$, which was markedly better than that reported for quantification of HTLV-1 proviral load (8.2\% to $31.4 \%$ [32] or $49 \%$ to $55 \%$ [33]). The high reproducibility of our assay enabled its use for the quantitation of proviral load during disease progression. The accuracy of BLV-CoCoMo-qPCR was also confirmed by sequencing analysis. We selected nine samples in which BLV provirus could be detected by BLV-CoCoMo-qPCR, but not by nested PCR, and sequenced the amplicons. Using this strategy, we confirmed that the nine samples were infected by BLV, and this highlights the ability of the BLV-CoCoMo-qPCR 
method to detect provirus in samples that were negative by nested PCR. In two of the nine samples, sequence mismatches were detected at the annealing region for the nested PCR primers, thereby suggesting an explanation for the failure of nested PCR to detect BLV in these samples.

The syncytia assay is a common strategy for detecting viable BLV virus particles [34]. However, this method requires cell culture, is time consuming and often difficult, and also has low sensitivity. We tested whether the proviral copy number obtained with our assay correlated with the syncytium formation assay, since this would suggest that our assay could be used for diagnosis at the BLV infection stage. Syncytia formation correlated strongly with a proviral load of over 10,000 copies $/ 10^{5}$ cells, as calculated by BLV-CoCoMo-qPCR. In BLVinfected cattle with a low proviral load detected by BLV-CoCoMo-qPCR, syncytia formation could hardly be detected. Thus, BLV-CoCoMo-qPCR appears to be capable of correctly determining the level of BLV infection in animals with low viral loads.

The pre-leukemic phase of BLV infection, called as $\mathrm{PL}$, is characterized by the expansion of infected surface immunoglobulin M-positive B-cells with proviral insertion at multiple sites. On the other hand, a unique integration site is characteristic of malignant of malignant B-cells found in BLV-infected individuals after the onset of overt leukemia/lymphoma [13,23,35]. According to this model, proviral load should increase during disease progression but this has not been formally demonstrated. Using BLV-CoCoMo-qPCR, we were able to detect an increase in proviral load during disease progression. This result strongly suggests that proviral load may be an excellent indicator for monitoring the progression of disease, but may also be useful for implementing segregation programs to minimize BLV transmission. Previous experiments also identified host factors or genetic backgrounds that correlate with disease progression. For example, tumorassociated c143 antigens have been identified that are serine phosphorylated specifically in cattle with EBL, and genetic polymorphisms in cancer-associated genes such as p53 and tumor necrosis factor (TNF) have also been linked with EBL [35-41]. Proviral load may also be a valuable measure for identifying markers that influence progression to the lymphoma stage. Our assay may be valuable for estimating the effectiveness of vaccination and may also be capable of detecting changes in proviral load in BLV-infected cattle with the TNF and BoLA alleles that have previously been associated with resistance or susceptibility to BLVinduced lymphoma. Finally, since our assay detected all BLV variants, the CoCoMo algorithm appears to be a useful tool for designing degenerate primers for the quantification of proviral loads of other retroviruses, including HTLV and HIV-1.

\section{Conclusions}

Using CoCoMo primers, we have developed a new quantitative real-time PCR method to measure the proviral load of known and novel BLV variants. Our method is highly specific, sensitive, quantitative and reproducible for detection of the BLV LTR region in infected animals. The method was effective in detecting BLV in cattle from a range of geographical locations, and detected BLV in a broader range of samples than the previously developed nested PCR. Finally, we have shown for the first time that the proviral load correlates well with the stage of disease progression.

\section{Methods}

\section{Clinical samples, cell lines and DNA extraction}

Blood samples were obtained from 117 healthy cattle with negative BLV serology, 163 BLV-infected cattle that were clinically and hematologically normal, 16 clinically normal BLV-infected cattle with PL, and 89 BLV-infected cattle with EBL. These cattle were all maintained in Japan. A further 116 cattle that were maintained in Bolivia, Peru, Chile and the U.S.A were included in the study. BLV-infected cattle were classified according to previously established criteria [42] and the genomic integrations of the BLV provirus. PBMCs were separated from blood by the method of Miyasaka and Trnka [43].

The BLV-infected B lymphoma cell line BLSC-KU-17 [44] was maintained in Dulbecco's modified Eagle's medium (Life Technologies Japan, Tokyo, Japan) supplemented with $10 \%$ heat-inactivated fetal calf serum (FCS) (Sigma Aldrich Chemie Gmbh, Steinem, Germany), penicillin and streptomycin. CC81, a cat cell line transformed by mouse sarcoma virus, was maintained in RPMI 1640 medium (Sigma-Aldrich Co. Ltd., Ayrshire, UK) supplemented with $10 \%$ heat-inactivated FCS, penicillin and streptomycin.

Genomic DNA was extracted from (a) whole blood by the DNA Wizard Genomic DNA purification Kit (Promega, Madison, WI), (b) PBMCs by the procedure described by Hughes et al. [45] and (c) $40 \mu \mathrm{l}$ of whole blood spotted on FTA elute cards (Whatman, Tokyo, Japan), using standard procedures.

\section{Design of primers and probes}

The 52 variants of individual BLV LTR sequences were selected from 356 BLV sequences in GenBank as shown in Additional files 1-3. The target sequences were subjected to a BLV LTR modified version of the CoCoMo-primerdesign algorithm (http://www.geneknot.jp/cocomo; Endoh D, Mizutani T, Morikawa S Hamaguchi I, Sakai K, 
Takizawa K, Osa Y, Asakawa M, Kon Y, Hayashi M, CoCoMo-Primers: a web server for designing degenerate primers for virus research. Submitted), which was developed for designing degenerate primers to detect multiple strains of viruses.

To detect specific PCR products, we used the TaqMan $^{\mathrm{TM}}$ probe system (Applied Biosystems, Tokyo, Japan), with probe sequences designed using Primer Express software, version 2.0 (Applied Biosystems).

\section{Plasmids}

To obtain pBLV-LTR/SK, which included a full-length LTR from BLV, we used PCR with the primers BLVLTR/XhoI (5'-CCCGCTCGAGTGTATGAAAGATCATGCCGA-3'; positions 1 to 20) and BLV-LTRR/ BamHI (5'-CGGGATCCTGTTTGCCGGTCTCTCCTGG-3'; positions 511 to 531) and genomic DNA extracted from BLSC-KU-17 cells as a template. PCR products were cloned into pBluescript II SK (+) (Stratagene, La Jolla, CA). The numbering of nucleotides corresponds to positions in the sequences determined by Derse et al. [46]. To generate pBoLA-DRA/SK, which includes a full-length bovine $D R A$ gene, we digested MR1 from the mammalian expression vector $\mathrm{PCDM} 8$ [47] with X $b a$ I. The Xba I-Xba I fragment including the MR1 sequence was then subcloned into pBluescript II SK (+) (Stratagene). Additional clones used included a BLV infectious clone, pBLV-IF [34]; a HTLV-1 infectious clone, pK30 [48]; a HIV-1 infectious clone, pNL43 [49]; a SIV infectious clone, SIVmac239/WT [50]; a hybrid MMTV provirus plasmid [51]; a M-MLV infectious clone, pL-4 [52] and plasmids including pUC18 (Takara Bio Inc., Tokyo, Japan), pUC19 (Takara Bio Inc.), and pBR322 (Promega).

Calculation of copy number by the serial dilution method pBLV-LTR/SK and pBoLA-DRA/SK were digested with Sca I and purified using a Sephadex G-50 column (GE Healthcare Japan, Tokyo, Japan). The genomic DNA was digested with Xho I in the presence of $5 \mathrm{mM}$ spermidine for $24 \mathrm{~h}$. The samples were diluted to serial tenfold dilutions with TE buffer [10 mM Tris- $\mathrm{HCl}$ ( $\mathrm{pH} 8.0)$ with $1 \mathrm{mM}$ ethylenediamine tetraacetic acid ] on-ice. To avoid DNA adsorption to the microtubes, super smooth processed tubes (BM4015 Platinum super polypropylene; BM bio, Tokyo, Japan) were used for the preparation of template for the standard curve.

Limiting dilutions were performed for linearized pBLV-LTR/SK, pBoLA-DRA/SK and genomic DNA. Detection of the BLV LTR gene and the BoLA-DRA gene from plasmid DNA was performed by real-time PCR with the CoCoMo primers 6 and 81, or the primers DRA643 and DRA734, respectively. The BLV LTR gene was also detected in genomic DNA using nested PCR.
At the dilution point at which amplification products were unable to be detected, PCRs were repeated 10 times and the frequency of negative results was calculated $(f(x=0))$. The copy numbers of the target genes were calculated according to a Poisson distribution model: $\lambda=-\log _{\mathrm{e}}(\mathrm{f}(\mathrm{x}=0))$, where $\lambda=$ average copy number of the target gene.

\section{PCR conditions for candidate CoCoMo primer sets for the} amplification of the BLV LTR

Touch-down PCR amplifications were carried out in a $20 \mu$ l volume of $1 \times$ buffer for rTaq DNA Polymerase (TOYOBO, Tokyo, Japan) containing 1.0 unit rTaq, 0.2 mM dNTPs, $1.0 \mathrm{mM} \mathrm{MgCl} 2,500 \mathrm{nM}$ of forward and reverse primers, and $1 \mu \mathrm{l}$ of 1:1000 diluted BLV LTR amplicon, which had been amplified from genomic DNA by nested PCR. PCR amplification was performed with a TGRADIENT thermocycler (Biometra, Göttingen, Germany) according to the following program: an initial denaturation at $95^{\circ} \mathrm{C}$ for $10 \mathrm{~min}$, followed by 40 cycles of $15 \mathrm{~s}$ at $95^{\circ} \mathrm{C}, 10 \mathrm{~s}$ at $60^{\circ} \mathrm{C}$ to $52^{\circ} \mathrm{C}$ (annealing temperature was gradually decreased from $60^{\circ} \mathrm{C}$ to $52^{\circ} \mathrm{C}$, by $0.2^{\circ} \mathrm{C}$ every three cycles) and $10 \mathrm{~s}$ at $72^{\circ} \mathrm{C}$. Five $\mu \mathrm{l}$ of PCR products was used for $2 \%$ agarose gel electrophoresis and amplification products were detected by ethidium bromide staining.

\section{Melting curve analysis for evaluating PCR specificity}

PCR amplifications took place in a total volume of $20 \mu \mathrm{l}$ of $1 \times$ LightCycler FastStart DNA Master SYBR Green I (Roche Diagnostics GmbH, Basel, Switzerland) containing $500 \mathrm{nM}$ of each of the CoCoMo primers, $3 \mathrm{mM}$ of $\mathrm{MgCl}_{2}$, and $30 \mathrm{ng}$ of genomic DNA. PCR amplifications were performed with a Light Cycler 2.0 (Roche Diagnostics $\mathrm{GmbH}$ ) according to the following program: an initial denaturation at $95^{\circ} \mathrm{C}$ for $10 \mathrm{~min}$, followed by 75 cycles of $15 \mathrm{~s}$ at $95^{\circ} \mathrm{C}, 5 \mathrm{~s}$ at $65^{\circ} \mathrm{C}$, and $9 \mathrm{~s}$ at $72^{\circ} \mathrm{C}$. The melting process was monitored by fluorescence of the DNA-binding SYBR Green I dye for the detection of double-stranded DNA.

\section{Detection of BLV LTR by nested PCR}

The first PCR amplification was done using the primers BLTRF-YR (5'-TGTATGAAAGATCATGYCGRC-3' LTR 1-21) and BLTRR (5'- AATTGTTTGCCGGTCTCTC-3' LTR 515-533). The amplifications were carried out in a total volume of $20 \mu \mathrm{l}$ of $1 \times$ buffer for rTaq DNA Polymerase (TOYOBO) containing $250 \mathrm{nM}$ of BLTRF-YR primer and BLTRR primer, 0.5 units of rTaq polymerase, $0.2 \mathrm{mM}$ dNTPs, $2.5 \mathrm{mM} \mathrm{MgCl}_{2}$, and $30 \mathrm{ng}$ of template DNA. PCR amplification was performed with a TGRADIENT thermocycler (Biometra) according to the following program: an initial denaturation at $94^{\circ} \mathrm{C}$ for $2 \mathrm{~min}$, followed by 35 cycles of $30 \mathrm{sec}$ at $94^{\circ} \mathrm{C}$, 
$30 \mathrm{sec}$ at $58^{\circ} \mathrm{C}$ and $30 \mathrm{~s}$ at $72^{\circ} \mathrm{C}$, and a final cycle of 5 min at $72^{\circ} \mathrm{C}$.

The second set of PCR amplifications was performed in a total volume of $20 \mu \mathrm{l}$ of $1 \times$ buffer for rTaq DNA Polymerase (TOYOBO) containing $250 \mathrm{nM}$ of 256 primer and 453 primer (see below), 0.5 units of rTaq polymerase, 0.2 $\mathrm{mM}$ of dNTPs, $2.5 \mathrm{mM}$ of $\mathrm{MgCl}_{2}$, and $1 \mu \mathrm{l}$ of first-round PCR product. The oligonucleotide sequences used in the second PCR were 256 (5'-GAGCTCTCTTGCTCCCGAGAC-3', LTR 256-276) and 453 (5'-GAAACAAACGCGGGTGCAAGCCAG-3', LTR 430-454), and have been described previously [23]. PCR amplification was performed with a TGRADIENT thermocycler (Biometra) according to the following program: an initial denaturation at $94^{\circ} \mathrm{C}$ for $2 \mathrm{~min}$, followed by 35 cycles of $30 \mathrm{~s}$ at $94^{\circ} \mathrm{C}, 30$ $\mathrm{s}$ at $58^{\circ} \mathrm{C}$ and $30 \mathrm{~s}$ at $72^{\circ} \mathrm{C}$, and a final cycle of $5 \mathrm{~min}$ at $72^{\circ}$ C. Five $\mu$ l of PCR products was used for $2 \%$ agarose gel electrophoresis and the PCR products were detected by ethidium bromide staining.

\section{Amplification, Cloning, and DNA sequencing of BLV LTR regions}

To analyze the nucleotide sequence of samples that were positive by BLV-CoCoMo-qPCR but negative by nested PCR, genomic DNA from BLV-infected cattle was subjected to amplification by PCR using MightyAmp DNA polymerase Ver.2 (TAKARA), KOD plus Neo (TOYOBO), and TaqMan Universal Master Mix II system (AB). BLV LTR specific oligonucleotide primers BLTR56F (5'-AACGTCAGCTGCCAGAAA-3'), BLTR 134F (5'-AAAATCCACACCCTGAGCTG-3'), CoCo Mo6, CoCoMo81, and BLTR544R (5'- ACGAGCCCCC AATTGTTT-3') were designed by reference to the LTR regions of BLV proviral sequences. The PCR products were subcloned into pGEM-T Easy vector (Promega) by TA cloning and the nucleotide sequence was determined by cycle sequencing using standard procedures.

\section{Syncytium formation assay}

The assay was performed according to a previously described procedure [15,22]. CC81 cells were grown for $72 \mathrm{~h}$ in a 6-cm-diameter dish and incubated with $4 \times$ $10^{5}$ PBMC from BLV-infected cattle in RPMI 1640 medium. Cells were fixed in May-Grunwald solution for 2 min and stained with Giemsa solution for $15 \mathrm{~min}$. After washing with water, cells were examined under a light microscope. Cells containing more than five nuclei were counted as syncytia.

\section{Statistical analysis}

Statistical analysis was conducted using R 2.10.1 statistical computing software. For multiple testing, a pairwise $t$ test was used for calculating pairwise comparisons between group levels with corrections. P-values of less than 0.05 were considered significant. Regression analysis was used to examine the correlation between the serial dilution method and the BLV-CoCoMo-qPCR method, and between the syncytium count and the provirus copy number.

\section{Additional material}

\begin{abstract}
Additional file 1: From the BLV sequences, 102 LTR sequences were selected based on GenBank annotations. We collected whole nucleotide sequence-data from GenBank (356 data, on 30th April, 2009). From the BLV sequences, we selected 102 LTR sequences based on GenBank annotations.

Additional file 2: LTR-network. From the 102 LTR sequences, we selected 85 sequences that were of sufficient sizes ( $>400 \mathrm{bp}$ ) to determine homologies, and assigned the sequences to major BLV LTR groups based on homology using a graphical approach with Pajek graphical software

Additional file 3: Selection of representative BLV LTR sequences. In the 85 LTR sequence data, we classified homologous sequence groups and selected one sequence each group. Resultantly, 52 sequences, which were representing sequence repertoire of BLV LTR sequence, were selected as the target-set for primer-design.
\end{abstract}

\section{Acknowledgements}

We thank Dr. Shingo Katoh for useful discussion; Mr. Keisuke Fukumoto, Miss. Yuki Matsumoto, Dr. Taku Miyasaka, Dr. Mariluz Arainga-Ramirez, Dr. Naohiko Kobayashi, Dr. Tamako Matsuhashi, Mrs. Konomi Kuramochi, Mrs. Etsuko Saito, Dr. Jiyun Kim, Mr. Kazunori Yamada and Mr. Tomoyuki Murakami for excellent technical assistance, kind help and suggestions; and Dr. Misao Onuma, Dr. Guangai Xue, Dr. Verónica Gabriela de la Barra Díaz, Dr. Guillermo Giovambattista, Dr. Enrique J. Pofcher, Dr. Hermelinda RiveraGeronimo, Dr. Hideki Saito, Dr. Tomas J. Acosta, Dr. Misao Kanemaki, Dr. Manuel L. Ortiz and Dr. Jorge Oltra for helpful sampling; We also thank Dr. Tomoyuki Miura, Dr. Akinori Ishimoto and Dr. Akio Adachi for kindly providing various provirus plasmids; We thank the NIH AIDS research and reference reagent program for kindly providing HTLV-1 provirus plasmid; We are grateful to the Support Unit for Bio-material Analysis, RIKEN BSI Research Resources Center, for help with sequence analysis. This work was supported by Grants-in-Aid for Scientific Research (A and B) and by a Grant from the Program for the Promotion of Basic and Applied Research for Innovations in Bio-oriented Industry.

\section{Author details}

'Viral Infectious Diseases Unit, RIKEN, 2-1 Hirosawa, Wako, Saitama 351-0198, Japan. ${ }^{2}$ Laboratory of Viral Infectious Diseases, Department of Medical Genome Sciences, Graduate School of Frontier Science, The University of Tokyo, Wako, Saitama 351-0198, Japan. ${ }^{3}$ National Institute of Livestock and Grassland Science, 768 Senbonmatsu, Nasushiobara, Tochigi 329-2793, Japan. ${ }^{4}$ School of Veterinary Medicine Department of Veterinary Medicine, Rakuno Gakuen University, 583 Midorimachi Bunkyodai Ebetsu, Hokkaido 069-8501 Japan.

\section{Authors' contributions}

MJ participated in all experiments, analyzed data and drafted the manuscript. ST carried out experiments, participated in the experimental design, analyzed data, and helped to draft the manuscript. KM participated in some experiments and sample collection. DE participated in the design of the CoCoMo primers. YA conceived the study, participated in experiments, participated in experimental design, coordinated experiments, and drafted the manuscript. All authors read and approved the final manuscript.

\section{Competing interests}

The authors declare that they have no competing interests.

Received: 21 May 2010 Accepted: 2 November 2010 Published: 2 November 2010 


\section{References}

1. Lloyd-Smith JO, George D, Pepin KM, Pitzer VE, Pulliam JR, Dobson AP, Hudson PJ, Grenfell BT: Epidemic dynamics at the human-animal interface. Science 2009, 326:1362-1367.

2. Tapper ML: Emerging viral diseases and infectious disease risks. Haemophilia 2006, 12(Suppl 1):3-7, discussion 26-28.

3. Endoh D, Mizutani T, Kirisawa R, Maki Y, Saito H, Kon Y, Morikawa S, Hayashi M: Species-independent detection of RNA virus by representational difference analysis using non-ribosomal hexanucleotides for reverse transcription. Nucleic Acids Res 2005, 33:e65.

4. Rose TM, Schultz ER, Henikoff JG, Pietrokovski S, McCallum CM, Henikoff S: Consensus-degenerate hybrid oligonucleotide primers for amplification of distantly related sequences. Nucleic Acids Res 1998, 26:1628-1635.

5. Bartl S: Amplification using degenerate primers with multiple inosines to isolate genes with minimal sequence similarity. Methods Mol Biol 1997, 67:451-457.

6. Moonka D, Loh EY: A consensus primer to amplify both alpha and beta chains of the human T cell receptor. J Immunol Methods 1994, 169:41-51.

7. Rose TM, Henikoff JG, Henikoff S: CODEHOP (COnsensus-DEgenerate Hybrid Oligonucleotide Primer) PCR primer design. Nucleic Acids Res 2003, 31:3763-3766

8. Katoh K, Toh H: Recent developments in the MAFFT multiple sequence alignment program. Brief Bioinform 2008, 9:286-298.

9. Gillet $N$, Florins A, Boxus M, Burteau C, Nigro A, Vandermeers F, Balon $H$, Bouzar AB, Defoiche J, Burny A, Reichert M, Kettmann R, Willems L: Mechanisms of leukemogenesis induced by bovine leukemia virus: prospects for novel anti-retroviral therapies in human. Retrovirology 2007, 4:18.

10. Alexandersen S, Carpenter S, Christensen J, Storgaard T, Viuff B, Wannemuehler Y, Belousov J, Roth JA: Identification of alternatively spliced mRNAs encoding potential new regulatory proteins in cattle infected with bovine leukemia virus. J Virol 1993, 67:39-52.

11. Kettmann R, Meunier-Rotival M, Cortadas J, Cuny G, Ghysdael J, Mammerickx M, Burny A, Bernardi G: Integration of bovine leukemia virus DNA in the bovine genome. Proc Natl Acad Sci USA 1979, 76:4822-4826.

12. Kettmann R, Deschamps J, Cleuter Y, Couez D, Burny A, Marbaix G: Leukemogenesis by bovine leukemia virus: proviral DNA integration and lack of RNA expression of viral long terminal repeat and 3 ' proximate cellular sequences. Proc Natl Acad Sci USA 1982, 79:2465-2469.

13. Kettmann R, Cleuter $Y$, Mammerickx M, Meunier-Rotival M, Bernardi G, Burny A, Chantrenne H: Genomic integration of bovine leukemia provirus: comparison of persistent lymphocytosis with lymph node tumor form of enzootic. Proc Natl Acad Sci USA 1980, 77:2577-2581.

14. Lagarias DM, Radke K: Transcriptional activation of bovine leukemia virus in blood cells from experimentally infected, asymptomatic sheep with latent infections. J Virol 1989, 63:2099-2107.

15. Aida $Y$, Miyasaka $M$, Okada $K$, Onuma $M$, Kogure $S$, Suzuki M, Minoprio $P$, Levy D, Ikawa Y: Further phenotypic characterization of target cells for bovine leukemia virus experimental infection in sheep. Am J Vet Res 1989, 50:1946-1951.

16. Wang CT: Bovine leukemia virus infection in Taiwan: epidemiological study. J Vet Med Sci 1991, 53:395-398.

17. Monti GE, Frankena K, Engel B, Buist W, Tarabla HD, de Jong MC: Evaluation of a new antibody-based enzyme-linked immunosorbent assay for the detection of bovine leukemia virus infection in dairy cattle. J Vet Diagn Invest 2005, 17:451-457.

18. Kurdi A, Blankenstein P, Marquardt O, Ebner D: [Serologic and virologic investigations on the presence of BLV infection in a dairy herd in Syria]. Berl Munch Tierarztl Wochenschr 1999, 112:18-23.

19. Zaghawa A, Beier D, Abd El-Rahim IH, Karim I, El-ballal S, Conraths FJ, Marquardt O: An outbreak of enzootic bovine leukosis in upper Egypt: clinical, laboratory and molecular-epidemiological studies. J Vet Med B Infect Dis Vet Public Health 2002, 49:123-129.

20. Schoepf KC, Kapaga AM, Msami HM, Hyera JM: Serological evidence of the occurrence of enzootic bovine leukosis (EBL) virus infection in cattle in Tanzania. Trop Anim Health Prod 1997, 29:15-19.

21. Tajima S, Aida Y: The region between amino acids 245 and 265 of the bovine leukemia virus (BLV) tax protein restricts transactivation not only via the BLV enhancer but also via other retrovirus enhancers. J Virol 2000, 74:10939-10949.
22. Tajima S, Takahashi M, Takeshima SN, Konnai S, Yin SA, Watarai S, Tanaka Y, Onuma $\mathrm{M}$, Okada $\mathrm{K}$, Aida $\mathrm{Y}$ : A mutant form of the tax protein of bovine leukemia virus (BLV), with enhanced transactivation activity, increases expression and propagation of BLV in vitro but not in vivo. J Virol 2003, 77:1894-1903

23. Tajima S, Ikawa Y, Aida Y: Complete bovine leukemia virus (BLV) provirus is conserved in BLV-infected cattle throughout the course of B-cell lymphosarcoma development. J Virol 1998, 72:7569-7576.

24. Moratorio G, Obal G, Dubra A, Correa A, Bianchi S, Buschiazzo A, Cristina J, Pritsch O: Phylogenetic analysis of bovine leukemia viruses isolated in South America reveals diversification in seven distinct genotypes. Arch Virol 2010, 155:481-489.

25. VanLeeuwen JA, Tiwari A, Plaizier JC, Whiting TL: Seroprevalences of antibodies against bovine leukemia virus, bovine viral diarrhea virus, Mycobacterium avium subspecies paratuberculosis, and Neospora caninum in beef and dairy cattle in Manitoba. Can Vet J 2006, 47:783-786.

26. Kobayashi S, Tsutsui T, Yamamoto T, Hayama Y, Kameyama K, Konishi M, Murakami K: Risk factors associated with within-herd transmission of bovine leukemia virus on dairy farms in Japan. BMC Vet Res 2010, 6:1.

27. Rodriguez SM, Golemba MD, Campos RH, Trono K, Jones LR: Bovine leukemia virus can be classified into seven genotypes: evidence for the existence of two novel clades. J Gen Virol 2009, 90:2788-2797.

28. Coulston J, Naif H, Brandon R, Kumar S, Khan S, Daniel RC, Lavin MF: Molecular cloning and sequencing of an Australian isolate of proviral bovine leukaemia virus DNA: comparison with other isolates. J Gen Virol 1990, 71(Pt 8):1737-1746.

29. Asfaw Y, Tsuduku S, Konishi M, Murakami K, Tsuboi T, Wu D, Sentsui H: Distribution and superinfection of bovine leukemia virus genotypes in Japan. Arch Virol 2005, 150:493-505.

30. Tong S, Chern SW, Li Y, Pallansch MA, Anderson LJ: Sensitive and broadly reactive reverse transcription-PCR assays to detect novel paramyxoviruses. J Clin Microbiol 2008, 46:2652-2658.

31. Lew A, Bock R, Miles J, Cuttell L, Steer P, Nadin-Davis S: Sensitive and specific detection of bovine immunodeficiency virus and bovine syncytial virus by 5' Taq nuclease assays with fluorescent 3' minor groove binder-DNA probes. J Virol Methods 2004, 116:1-9.

32. Moens B, Lopez G, Adaui V, Gonzalez E, Kerremans L, Clark D, Verdonck K, Gotuzzo E, Vanham G, Cassar O, Gessain A, Vandamme AM, Van Dooren S: Development and validation of a multiplex real-time PCR assay for simultaneous genotyping and human T-lymphotropic virus type 1, 2 and 3 proviral load determination. J Clin Microbiol 2009, 47:3682-3691.

33. Dehee A, Cesaire R, Desire N, Lezin A, Bourdonne O, Bera O, Plumelle Y, Smadja D, Nicolas JC: Quantitation of HTLV-I proviral load by a TaqMan real-time PCR assay. J Virol Methods 2002, 102:37-51.

34. Inabe $K$, Ikuta $K$, Aida $Y$ : Transmission and propagation in cell culture of virus produced by cells transfected with an infectious molecular clone of bovine leukemia virus. Virology 1998, 245:53-64.

35. Aida Y, Okada K, Onuma M: Antigenic regions defined by monoclonal antibodies on tumor-associated antigens of bovine leukemia virusinduced lymphosarcoma cells. Leuk Res 1993, 17:187-193.

36. Aida Y, Okada K, Ohtsuka M, Amanuma H: Tumor-associated M(r) 34,000 and $M(r) 32,000$ membrane glycoproteins that are serine phosphorylated specifically in bovine leukemia virus-induced lymphosarcoma cells. Cancer Res 1992, 52:6463-6470.

37. Aida Y, Okada K, Amanuma H: Phenotype and ontogeny of cells carrying a tumor-associated antigen that is expressed on bovine leukemia virusinduced lymphosarcoma. Cancer Res 1993, 53:429-437.

38. Aida $\mathrm{Y}$, Onuma M, Mikami T, Izawa H: Topographical analysis of tumorassociated antigens on bovine leukemia virus-induced bovine lymphosarcoma. Cancer Res 1985, 45:1181-1186.

39. Aida $Y$, Nishino $Y$, Amanuma $H$, Murakami $K$, Okada $K$, Ikawa $Y$ : The role of tumor-associated antigen in bovine leukemia virus-induced lymphosarcoma. Leukemia 1997, 11(Suppl 3):216-218.

40. Tajima S, Zhuang WZ, Kato MV, Okada K, Ikawa Y, Aida Y: Function and conformation of wild-type $\mathrm{p} 53$ protein are influenced by mutations in bovine leukemia virus-induced B-cell lymphosarcoma. Virology 1998 243:735-746

41. Konnai S, Usui T, Ikeda M, Kohara J, Hirata T, Okada K, Ohashi K, Onuma M: Tumor necrosis factor-alpha genetic polymorphism may contribute to progression of bovine leukemia virus-infection. Microbes Infect 2006, 8:2163-2171 
42. Levy D, Deshayes L, Guillemain B, Parodi AL: Bovine leukemia virus specific antibodies among French cattle. I. Comparison of complement fixation and hematological tests. Int J Cancer 1977, 19:822-827.

43. Miyasaka M, Reynolds J, Dudler L, Beya MF, Leiserson W, Trnka Z: Differentiation of B lymphocytes in sheep. II. Surface phenotype of B cells leaving the 'bursa-equivalent' lymphoid tissue of sheep, ileal Peyer's patches. Adv Exp Med Biol 1985, 186:119-126.

44. Onuma M, Koyama H, Aida Y, Okada K, Ogawa Y, Kirisawa R, Kawakami Y: Establishment of B-cell lines from tumor of enzootic bovine leukosis. Leuk Res 1986, 10:689-695.

45. Hughes SH, Shank PR, Spector DH, Kung HJ, Bishop JM, Varmus HE, Vogt PK, Breitman ML: Proviruses of avian sarcoma virus are terminally redundant, co-extensive with unintegrated linear DNA and integrated at many sites. Cell 1978, 15:1397-1410.

46. Derse D, Diniak AJ, Casey JW, Deininger PL: Nucleotide sequence and structure of integrated bovine leukemia virus long terminal repeats. Virology 1985, 141:162-166.

47. Aida Y, Kohda C, Morooka A, Nakai Y, Ogimoto K, Urao T, Asahina M: Cloning of CDNAs and the molecular evolution of a bovine MHC class II DRA gene. Biochem Biophys Res Commun 1994, 204:195-202.

48. Zhao TM, Robinson MA, Bowers FS, Kindt TJ: Characterization of an infectious molecular clone of human T-cell leukemia virus type I. J Virol 1995, 69:2024-2030.

49. Adachi A, Gendelman HE, Koenig S, Folks T, Willey R, Rabson A, Martin MA: Production of acquired immunodeficiency syndrome-associated retrovirus in human and nonhuman cells transfected with an infectious molecular clone. J Virol 1986, 59:284-291.

50. Guan Y, Whitney JB, Detorio M, Wainberg MA: Construction and in vitro properties of a series of attenuated simian immunodeficiency viruses with all accessory genes deleted. J Virol 2001, 75:4056-4067.

51. Shackleford GM, Varmus HE: Construction of a clonable, infectious, and tumorigenic mouse mammary tumor virus provirus and a derivative genetic vector. Proc Natl Acad Sci USA 1988, 85:9655-9659.

52. Ishimoto A, Takimoto M, Adachi A, Kakuyama M, Kato S, Kakimi K, Fukuoka K, Ogiu T, Matsuyama M: Sequences responsible for erythroid and lymphoid leukemia in the long terminal repeats of Friend-mink cell focus-forming and Moloney murine leukemia viruses. J Virol 1987, 61:1861-1866

doi:10.1186/1742-4690-7-91

Cite this article as: Jimba et al: BLV-CoCoMo-qPCR: Quantitation of bovine leukemia virus proviral load using the CoCoMo algorithm. Retrovirology 2010 7:91.

\section{Submit your next manuscript to BioMed Central and take full advantage of:}

- Convenient online submission

- Thorough peer review

- No space constraints or color figure charges

- Immediate publication on acceptance

- Inclusion in PubMed, CAS, Scopus and Google Scholar

- Research which is freely available for redistribution

Submit your manuscript at www.biomedcentral.com/submit
Biomed Central 